\title{
Paraventricular Hypothalamic Regulation of Trigeminovascular Mechanisms Involved in Headaches
}

\author{
Claude Robert, ${ }^{1 \star}$ Laurence Bourgeais, ${ }^{1 \star}$ Charles-Daniel Arreto, ${ }^{1}$ Miguel Condes-Lara, ${ }^{2}$ Rodrigo Noseda, ${ }^{3}$ Thérèse Jay, ${ }^{1}$ \\ and Luis Villanueva ${ }^{1}$ \\ ${ }^{1}$ Institut National de la Santé et de la Recherche Médicale/Université Paris Descartes UMR 894, Centre de Psychiatrie et Neurosciences, 75014 Paris, France, \\ 2Instituto de Neurobiología, Campus Universidad Nacional Autonoma de Mexico-Juriquilla, 76230 Querétaro, Mexico, and ${ }^{3}$ Department of Anesthesia, \\ Beth Israel Deaconess Medical Center, Harvard Medical School, Boston, Massachusetts 02215
}

While functional imaging and deep brain stimulation studies point to a pivotal role of the hypothalamus in the pathophysiology of migraine and trigeminal autonomic cephalalgias, the circuitry and the mechanisms underlying the modulation of medullary trigeminovascular (Sp5C) neurons have not been fully identified. We investigated the existence of a direct anatomo-functional relationship between hypothalamic excitability disturbances and modifications of the activities of Sp5C neurons in the rat. Anterograde and retrograde neuronal anatomical tracing, intrahypothalamic microinjections, extracellular single-unit recordings of Sp5C neurons, and behavioral trials were used in this study. We found that neurons of the paraventricular nucleus of the hypothalamus (PVN) send descending projections to the superior salivatory nucleus, a region that gives rise to parasympathetic outflow to cephalic and ocular/nasal structures. PVN cells project also to laminae I and outer II of the Sp5C. Microinjections of the $\mathrm{GABA}_{\mathrm{A}}$ agonist muscimol into $\mathrm{PVN}$ inhibit both basal and meningeal-evoked activities of Sp5C neurons. Such inhibitions were reduced in acutely restrained stressed rats. $\mathrm{GABA}_{\mathrm{A}}$ antagonist gabazine infusions into the PVN facilitate meningeal-evoked responses of Sp5C neurons. PVN injections of the neuropeptide pituitary adenylate cyclase activating peptide (PACAP38) enhance Sp5C basal activities, whereas the antagonist PACAP6-38 depresses all types of Sp5C activities. 5- $\mathrm{HT} 1_{\mathrm{B} / \mathrm{D}}$ receptor agonist naratriptan infusion confined to the PVN depresses both basal and meningeal-evoked Sp5C activities. Our findings suggest that paraventricular hypothalamic neurons directly control both spontaneous and evoked activities of Sp5C neurons and could act either as modulators or triggers of migraine and/or trigeminal autonomic cephalalgias by integrating nociceptive, autonomic, and stress processing mechanisms.

\section{Introduction}

Preclinical data suggest that primary headaches are initiated by the activation of meningeal perivascular nociceptors that in turn activate brainstem trigeminovascular (Sp5C) neurons (Burstein et al., 1998). Although the mechanisms by which the trigeminovascular pathway become activated in the first place have not been fully established, there is a variety of endogenous headache triggers such as hypothalamic-related maladaptive changes that have been proposed as a common determinant factor on the susceptibility to both migraine (Zurak, 1997; Alstadhaug, 2009) and trigeminal autonomic cephalalgias (TACs) (Leone et al., 2001; May, 2009).

Cranial autonomic manifestations, including reddening of the eye, tearing, rhinorrhea, and eyelid edema, which commonly

\footnotetext{
Received Jan. 30, 2013; revised March 20, 2013; accepted April 14, 2013.

Author contributions: T.J. and L.V. designed research; C.R., L.B., C.-D.A., M.C.-L., and R.N. performed research; C.R., L.B., C.-D.A., M.C.-L., R.N., and L.V. analyzed data; C.R., L.B., R.N., T.J., and L.V. wrote the paper.

This work was supported by grants from INSERM and Association Gliaxone, CONACyT-Mexico Grant 164536, and a 2011 IASP Developing Country Collaborative Research grant. We thank Maryse Chalus for her technical contribution during the early phase of this work. Parts of this paper have been published previously in abstract form.

${ }^{*}$ C.R. and L.B. contributed equally to this work.

The authors declare no competing financial interests.

Correspondence should be addressed to Dr. Luis Villanueva, Centre de Psychiatrie et Neurosciences, INSERM UMR894, 2 Ter Rue d'Alésia, 75014 Paris, France. E-mail: luis.villanueva@inserm.fr.

DOI:10.1523/JNEUROSCI.0439-13.2013

Copyright $\odot 2013$ the authors $\quad 0270-6474 / 13 / 338827-14 \$ 15.00 / 0$
}

accompany TACs and to a lesser extent migraine, are likely mediated by dysfunctional changes in hypothalamic structures that integrate and drive autonomic responses. In addition, the episodic nature of migraine attacks and TACs has been related to circadian rhythmicity, hormonal fluctuations, and stress, further implicating hypothalamic involvement in the initiation of the headache. Likewise, functional imaging studies have clearly observed hypothalamic abnormal activity during migraine (Denuelle et al., 2007) and the different types of TACs (May et al., 1998, 1999; Matharu et al., 2004, 2006). A proof of concept for has been established through the therapeutically effective use of posterior hypothalamic stimulation in TACs patients (Leone et al., 2001). However, the specific hypothalamic mechanisms involved in the initiation of the headache and autonomic outflow during migraine and TACs remain to be explored.

The overall aim of this study was to investigate the existence of a direct relationship between hypothalamic excitability disturbances and the activities of rat Sp5C neurons involved in meningeal nociceptive processing. For this purpose, we studied the functional architecture of hypothalamic networks that could directly modulate brainstem Sp5C neurons. Initially, we examined the fine topographic organization of hypothalamo-trigeminal projections with high-resolution retrograde and anterograde anatomical tracing under electrophysiological control. On the basis of the resulting data, additional series of experiments were designed to perform extracellular recordings of Sp5C neurons. In 


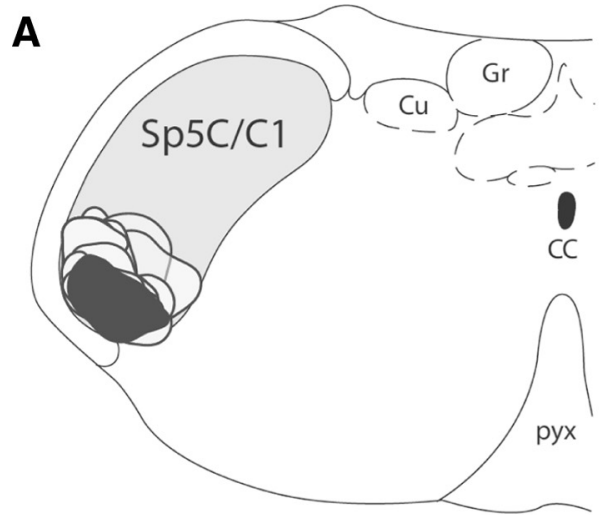

B

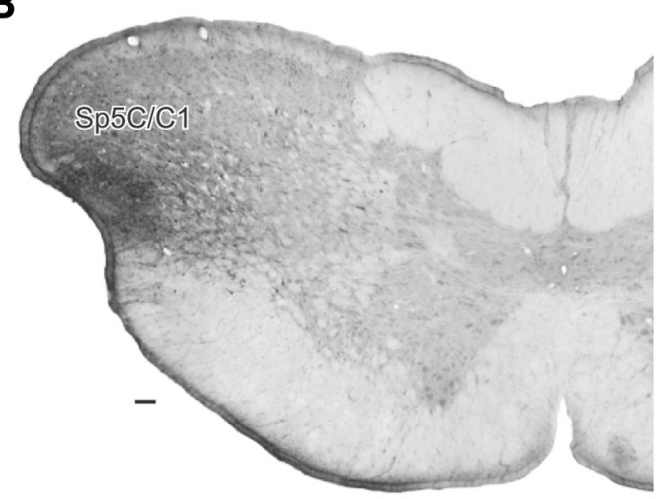

C
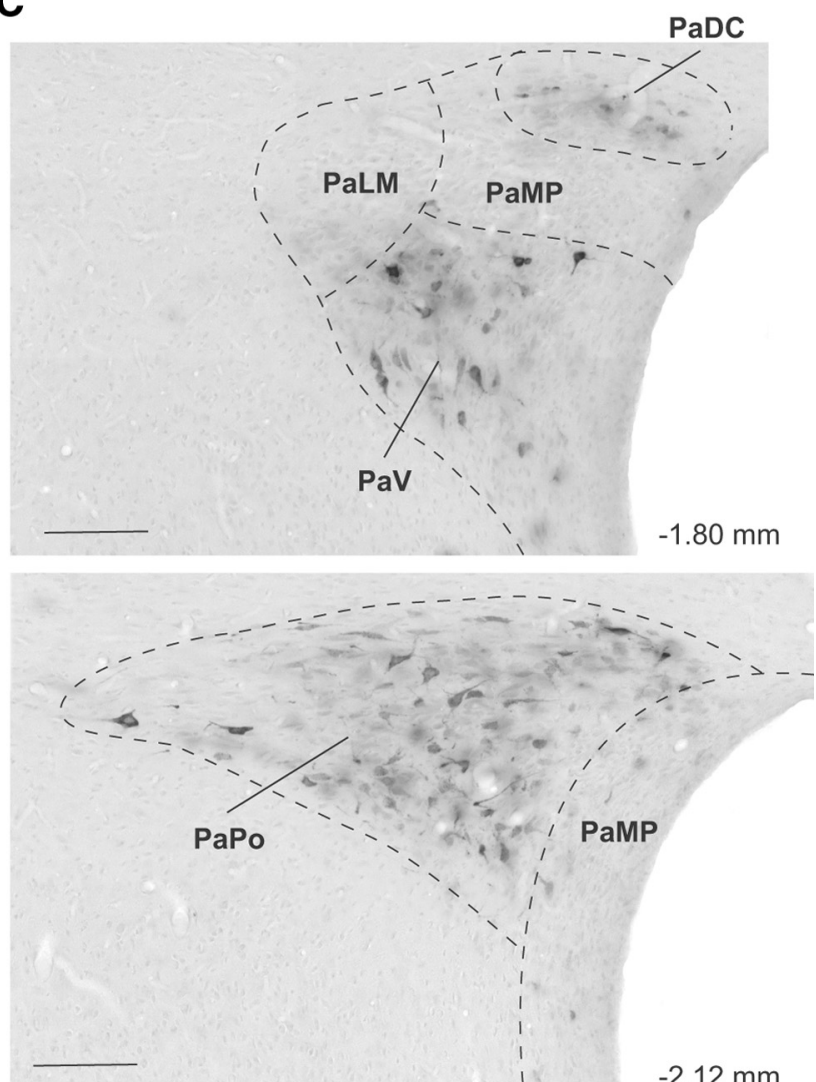

$-2.12 \mathrm{~mm}$

Figure 1. Paraventricular hypothalamic neurons retrogradely labeled from the ophthalmic branch of the $\mathrm{Sp5C.} A$, Camera lucida drawings of coronal sections, illustrating the location and extent of all FG injection sites (gray, selected site in black) into the $\mathrm{Sp} 5 \mathrm{C} / \mathrm{C} 1$ area containing dura-sensitive neurons with periocular receptive fields, recorded before a Fluorogold injection. one set of experiments, basal activities and Sp5C-evoked responses following meningeal electrical stimulation were recorded before and after GABAergic, pituitary adenylate cyclase activating peptide (PACAP), and $5-\mathrm{HT} 1_{\mathrm{B} / \mathrm{D}}$ receptor agonist (naratriptan) microinjections within the paraventricular nucleus of the hypothalamus (PVN). In another experimental series, the $\mathrm{GABA}_{\mathrm{A}}$ agonist muscimol was microinjected within the PVN in an acute restrained stress model to investigate whether top-down influences from the PVN onto Sp5C neurons are modified by stress.

Parts of this paper have been published previously in abstract form (Bourgeais et al., 2008; Robert et al., 2012).

\section{Materials and Methods}

General. Adult male Sprague Dawley rats (Charles River Laboratories) weighing 200-300 g were used in this study. All animal experiments were approved by our local animal care committee and were in accordance with the guidelines of the International Association for the Study of Pain (Zimmermann, 1983).

Electrophoretic injections of the retrograde tracer Fluorogold into Sp5C. The rats were anesthetized with chloral hydrate $(400 \mathrm{mg} / \mathrm{kg}$, i.p.) and mounted in a stereotaxic device. The atlanto-occipital membrane and the overlying dura were removed. Glass micropipettes ( $40 \mu \mathrm{m}$ diameter tips) filled with a $2 \%$ solution of hydroxystilbamidine (Fluorogold; Interchim) were positioned at $2700-4000 \mu \mathrm{m}$ caudal to the obex and inserted into the ventrolateral aspect of the Sp5C. Multiunitary recordings of cells responding to tactile and noxious pinch stimuli of the ophthalmic dermatome of the trigeminal nerve were performed. Once these cells were encountered, direct positive currents $(6-10 \mu \mathrm{A}$, on-off cycles of $10 \mathrm{~s})$ were applied for $15 \mathrm{~min}$. Then, the surgical wounds were sutured and disinfected. Each animal was kept in an individual cage for $72 \mathrm{~h}$ and reanesthetized with an overdose of chloral hydrate $(800 \mathrm{mg} / \mathrm{kg}$, i.p. $)$ and perfused with $200 \mathrm{ml}$ of warm $\left(37^{\circ} \mathrm{C}\right)$ heparinized saline, followed by 500 $\mathrm{ml}$ of PBS $(0.2 \mathrm{M}), \mathrm{pH} 7.3$, containing $4 \%$ paraformaldehyde and $0.05 \%$ picric acid. The brain and medulla were removed and soaked in the latter solution for $2 \mathrm{~h}$ and then cryoprotected in a buffered $30 \%$ sucrose solution. Two days later, $40-\mu \mathrm{m}$-thick coronal sections were rinsed with PBS and divided into three groups. The sections of one group were preincubated for $1 \mathrm{~h}$ in a blocking solution of PBS containing $0.3 \%$ Triton X-100 and $0.3 \%$ bovine serum albumin (PBT) and $2 \%$ normal goat serum (NGS). They were then incubated overnight in the primary antibody, namely, 1:5000 rabbit anti-Fluorogold (Millipore Bioscience Research Reagents) in PBT and 2\% NGS. After 20 min rinsing with PBS, the sections were incubated for $1 \mathrm{~h}$ in the secondary antiserum, namely, 1:200 biotinylated goat anti-rabbit $\operatorname{IgG}$ (Interchim) in PBT and 2\% NGS. After rinsing with $\mathrm{PBS}$, the sections were processed for $\mathrm{ABC} /$ $\mathrm{DAB}$ (Vector Laboratories) to localize the retrograde labeling in different brain structures.

Electrophoretic injections of the anterograde tracer biotin dextran into the $P V N$. The rats were anesthetized with chloral hydrate $(400 \mathrm{mg} / \mathrm{kg}$, i.p.) and mounted in a stereotaxic device, and a craniotomy was performed. Glass micropipettes ( $40 \mu \mathrm{m}$ diameter tips) filled with a $10 \%$ solution of biotin dextran (BD; 10,000 molecular weight; Invitrogen) were inserted into the the parvocellular aspect of the PVN 800-1200 $\mu \mathrm{m}$ caudal to bregma, 1900-2300 $\mu \mathrm{m}$ lateral to the midline, at a depth of 7200-7800 $\mu \mathrm{m}$ (Paxinos and Watson, 1998). Once the micropipette was placed in the desired position, direct positive current $(2-4 \mu \mathrm{A})$ was applied for $20 \mathrm{~s}$

$\leftarrow$

B, Photomicrograph of the selected site. $\boldsymbol{C}$, Retrogradelly labeled cells in the hypothalamus (adapted from Paxinos and Watson, 1983). Note that labeled cells were confined to the ipsilateral parvocellular region of the PVN, covering between -2.12 and $-1.80 \mathrm{~mm}$ caudal to bregma. All of these injection sites provided similar patterns of retrograde labeling within the PVN. Scale bars, $100 \mu \mathrm{m}$. PaDC, Paraventricular hypothalamic nucleus, dorsal cap; PaLM, paraventricular hypothalamic nucleus, lateral magnocellular part; PaMP, paraventricular hypothalamic nucleus, medial parvicellullar part; $\mathrm{PaP}$, paraventricular hypothalamic nucleus, posterior part; ventral part; CC, central canal; $\mathrm{Cu}$, cuneate nucleus; $\mathrm{Gr}$, gracile nucleus; $\mathrm{PaV}$, paraventricular hypothalamic nucleus. Numbers indicate distance from bregma. 
A

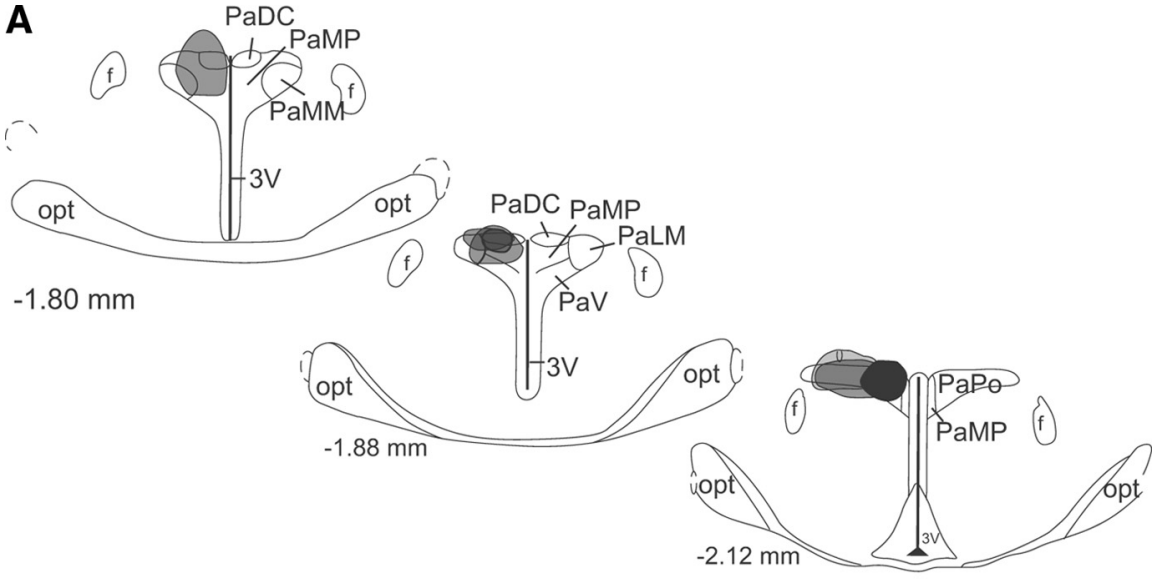

B

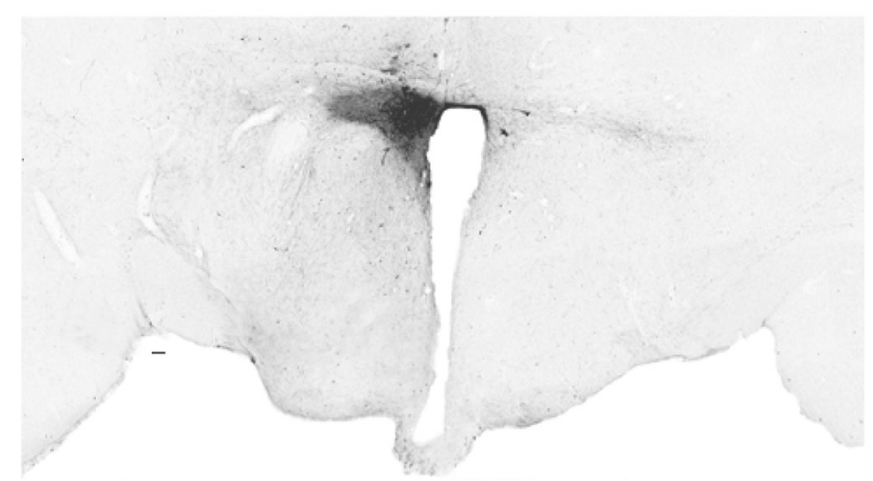

C

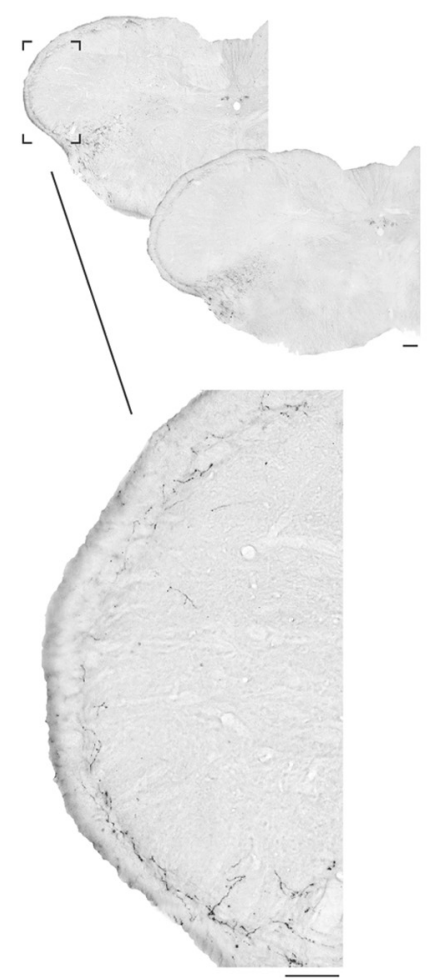

D

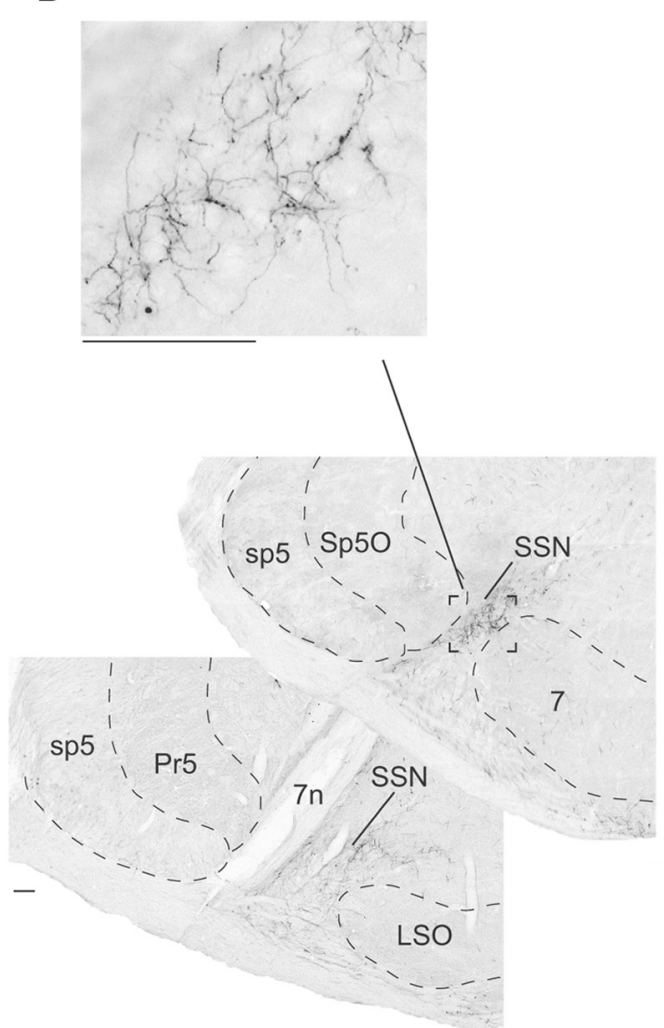

Figure 2. Descending axonal projections of PVN neurons. $A$, Coronal view of BD injection sites confined to the parvocellular region of the PVN. All PVN injection sites are represented in gray and the selected site in black. $\boldsymbol{B}$, Photograph of the selected site in black (left). $\boldsymbol{C}$, Bright-field images of labeling in a coronal section of the caudal medulla. Note the high density of terminal labeling in the superficial layers (I- outer II) of the ipsilateral trigeminal nucleus caudalis (Sp5C). D, Bright-field images of labeling in a coronal section of the rostral brainstem. Note the (Figure legend continues.) 
every $30 \mathrm{~s}$ for $15-20 \mathrm{~min}$. Following a postoperative survival period of 1 week, the animals were reanesthetized and perfused as described previously (Noseda et al., 2008). The brain and medulla were removed, postfixed, and cryoprotected. Two days later, the $40-\mu \mathrm{m}$-thick coronal sections were rinsed with PBS. The sections were divided into three groups. Two groups were processed for $\mathrm{ABC} / \mathrm{DAB}$ histochemistry to localize the anterograde labeling in different brain structures; one of these groups was counterstained with cresyl violet.

Analysis of the retrograde and anterograde labeling. In all the tracttracing experimental series, the injection sites, labeled cell bodies, fibers, varicosities, and boutons were examined under bright- and dark-field illumination. Each injection site was analyzed using camera lucida drawings of coronal sections processed with DAB. Representative cases including the full extents of the injection sites were grouped on standard drawings of the caudal medulla and PVN areas. Bright-field photomicrographs of the injection sites and representative labeling were built as digitized gray scale images using computer-assisted reconstruction of labeling. The technique used has been described in detail previously (Villanueva and Le Bars, 1993). The delineation and nomenclature of brainstem and supramedullary areas were based on the atlas of Paxinos and Watson (1998). The areas of interest were also fully identified in our counterstained material.

Unitary extracellular recordings. Rats were introduced in a chamber and deeply anesthetized with $2.5 \%$ isofluorane $(1000 \mathrm{mg} / \mathrm{ml}$ solution; Virbac) placed in a vaporizer that mixes the anesthetic solution with air. Cannulas were inserted into the trachea, a carotid artery, and a jugular vein. Once the animals were intubated following tracheostomy, the anesthetic mixture was delivered at a rate of $100 \mathrm{ml} / \mathrm{min}$. The rats were paralyzed by intravenous injection of gallamine triethiodide $(10 \mathrm{mg} / \mathrm{h}$; Rhone-Poulenc Rorer) and artificially ventilated at a rate of 52 strokes/ min. The stroke volume was adjusted to maintain a normal acid-base equilibrium assessed using a Datex-Ohmeda (GE Healthcare) compact monitor. This capnometer continuously measured respiratory frequency, end-tidal, inspired and expired $\mathrm{CO}_{2}, \mathrm{O}_{2}$, and isofluorane levels via a catheter in the tracheal space. These parameters were displayed digitally, and each was under the control of an alarm. Each animal was mounted in a stereotaxic frame, and a craniotomy was performed at the lambdoid suture on the right side of the skull to allow placement of a stimulating electrode on the dura overlying the transverse sinus. A second craniotomy was performed on the right side of the skull $[1.4 \mathrm{~mm}$ behind the coronal suture; $2.5 \mathrm{~mm}$ lateral to the midline, according to the coordinates of Paxinos and Watson (1998)] to access the hypothalamus for drug microinjections. The atlanto-occipital membrane was removed, and a partial laminectomy of $\mathrm{C} 1$ was done to allow access to the caudal brainstem/cervicomedullary junction, where most of the trigeminovascular cells responding to the dura are located (Burstein et al., 1998; Noseda et al., 2010). Once the surgical procedures were finished, the level of anesthesia was lowered to $1.5 \%$ isofluorane. Extracellular single units were recorded using glass micropipettes or quartz-insulated, platinumtungsten microelectrodes custom ground to impedances of 4-6 M $\Omega$. In the latter case, five electrodes were positioned $300 \mu \mathrm{m}$ apart in the mediolateral axis on the Sp5C/C1 region between 2700 and $4000 \mu \mathrm{m}$ caudal to the obex and advanced into the brainstem independently using a five-channel Eckhorn mini-matrix microdrive system (Thomas Recordings). This device allows the insertion of thin shaft probes into neural tissue by a stretched elastic rubber tube in which the quartz-insulated, platinum-tungsten electrodes are guided (Eckhorn and Thomas, 1993). This system enables smooth movements performed with independently advanceable electrodes. Moreover, the electrodes are quite thin $(60 \mu \mathrm{m}$ shaft; $10 \mu \mathrm{m}$ tip diameters), but strong enough to penetrate the dura,

$\leftarrow$

(Figure legend continued.) high density of terminal labeling confined to the SSN. All of the injection sites provided similar patterns of anterograde labeling within the $\mathrm{Sp} 5 \mathrm{C}$ and $\mathrm{SSN}$. 7, Facial nucleus; $3 \mathrm{~V}$, third ventricle; $7 \mathrm{n}$, facial nerve; f, fornix; LSO, lateral superior olive; opt, optic tract; PaMM, paraventricular hypothalamic nucleus, medial magnocellular part; $\mathrm{PaPo}$, paraventricular hypothalamic nucleus, posterior part; sp5, spinal trigeminal tract; $5 p 50$, spinal trigeminal nucleus, oral part. Numbers indicate distance from bregma. Scale bars, $100 \mu \mathrm{m}$. thus reducing the damage to the neural tissue. Microelectrode signals were amplified, filtered, digitized, and discriminated with a CED hardware and Spike 2 software (version 7, Cambridge Electronic Design). Raw and discriminated signals were fed through an audio monitor and displayed on an oscilloscope for additional inspection. Waveforms and recorded spike trains were stored on computer disk for off-line analyses. Baseline and evoked activities of trigeminovascular neurons were recorded and analyzed as cumulative frequency and poststimulus histograms (PSTHs), to detect the occurrence of statistically significant neuronal responses. PSTH analysis of noxious meningeal stimulation was expressed as the total number of spikes triggered by trains of single electrical pulses. On the basis of the literature (Levy and Strassman, 2002), and taking into account the distance between the stimulated area and the recording electrode, the peak latencies observed in our study correspond to peripheral conduction velocities within the $\mathrm{A} \delta$ - and $\mathrm{C}$-fiber ranges, respectively. Accordingly, we used time frame windows of $0-30 \mathrm{~ms}$ and $30-100 \mathrm{~ms}$ for measuring $\mathrm{A} \delta$ - and C-fibers activities, respectively, and 100-150 ms for afterdischarges. Background neuronal discharges were expressed in hertz.

Intrahypothalamic administration of drugs. We tested the effects of a $\mathrm{GABA}_{\mathrm{A}}$ agonist and antagonist (muscimol, $8.7 \mathrm{~mm}, 200 \mathrm{nl}$; gabazine, 50 $\mu \mathrm{M}, 200 \mathrm{nl}$ dissolved in saline; Sigma-Aldrich), pituitary adenylate cyclase activating peptide agonist and antagonist (PACAP38, $50 \mu \mathrm{M}, 500 \mathrm{nl}$; PACAP6-38, $200 \mu \mathrm{M}, 500 \mathrm{nl}$ dissolved in saline; Bachem), and naratriptan $(10 \mu \mathrm{M}, 200 \mathrm{nl}$ dissolved in saline; Sigma-Aldrich $)$ within the parvocellular part of the PVN on baseline and evoked trigeminovascular neuronal responses. Drugs were injected at a rate of $1 \mathrm{nl} / \mathrm{s}$ using a Hamilton syringe (200 $\mu \mathrm{m}$ tip) driven by an electronic geared syringe pump (Ultra Micropump, UMP3; WPI) that allowed us to minimize the damage to the brain tissue. The specificity of the paraventricular hypothalamic effects of all drugs tested was confirmed by the systematic lack of changes on both Sp5C activities and physiological parameters (respiratory, cardiovascular) following microinjections placed adjacent to $\mathrm{PVN}$ regions projecting to $\mathrm{Sp} 5 \mathrm{C}$ (see Fig. 3). At the conclusion of the experiments, the recording and microinjection sites were marked by deposition of $500 \mathrm{nl}$ of pontamine sky blue and examined in Nissl-counterstained tissue.

Experimental design: innocuous and noxious stimulation. A first search of cells responding to tactile stimulation of the ophthalmic dermatome of the trigeminal nerve was performed. Once these clusters of $\mathrm{Sp5C}$ cells were encountered, a systematic search was performed for dura-sensitive Sp5C neurons responding to electrical stimulation (1 $\mathrm{Hz} ; 0.8 \mathrm{~ms}$ duration; $1 \mathrm{~mA}$ ) of the transverse sinus (see Fig. 3 ). Once a neuron responding to such search stimuli was found, a 10-20 min resting period was allowed to permit the neuron to return to its steady-state baseline activity, thus making possible accurate measurements of preinjection, control background activities. Mean background activity was calculated for each cell from a $200 \mathrm{~s}$ period before each test. Sets of controls consisting of measurements of baseline activity followed by meningeal electrical stimuli (approximately onefold C-fiber threshold intensity) were applied before microinjections into PVN. Postinjection tests were performed at 5 min intervals during 60-120 min to observe the effects of each drug and the temporal evolution of spontaneous and evoked activities of Sp5C neurons.

Stress protocol. The behavioral stress protocol used in this study was described previously (Xu et al., 1998; Rocher et al., 2004). Briefly, rats $(n=8)$ were placed on an elevated and unsteady platform $(21 \times 20 \mathrm{~cm})$ for $30 \mathrm{~min}$. The platform was positioned $1 \mathrm{~m}$ above the ground and illuminated at a $50 \mathrm{~cm}$ distance with a high-intensity light source (1500 lux). While on the platform, all animals showed signs of stress such as increased urination, defecation, grooming, and freezing. Ten minutes after the stress procedure, rats were anesthetized with a mixture of $2.5 \%$ isoflurane and air. Following anesthesia and before surgery, blood samples of control and stressed animals were collected from the orbital sinus. As a biomarker of stress, plasma levels of corticosterone were determined using an enzyme immunoassay (ELISA Kit ADI-900-097; Enzo Life Sciences). According to the manufacturer's protocol, the intra-assay coefficient of variation was $6.6 \%$, and the sensitivity was $27.0 \mathrm{pg} \mathrm{ml}^{-1}$. Rats were then prepared for electrophysiological recordings as described above. 
A

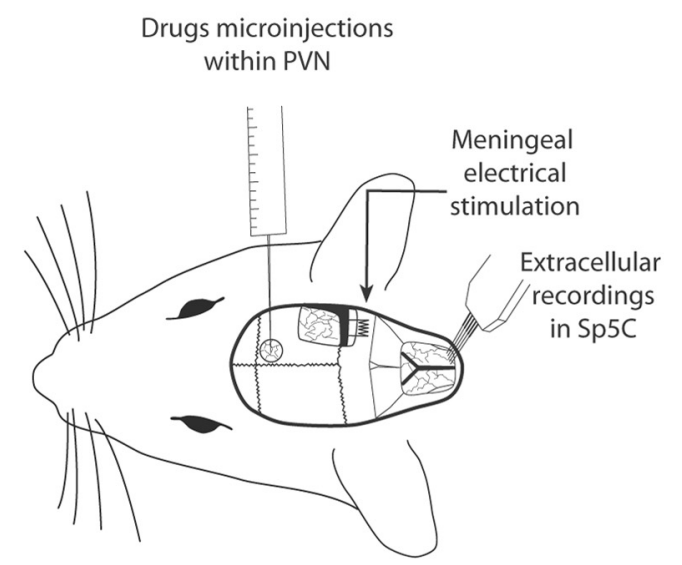

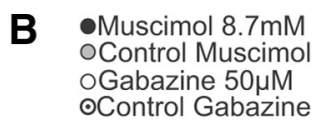
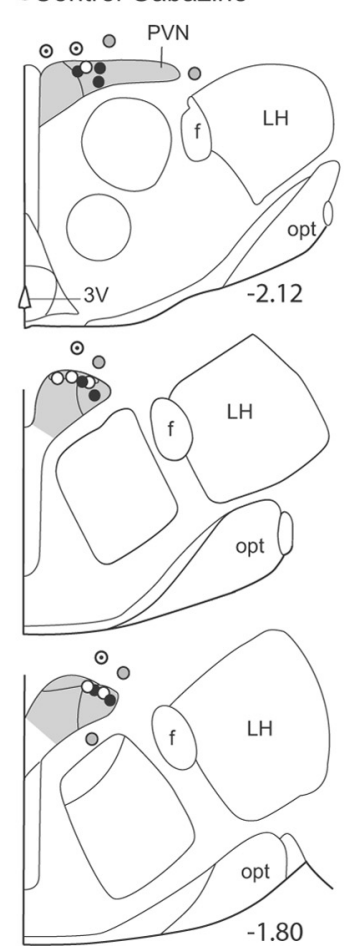

PACAP38 50 $4 \mathrm{M}$
OControl PACAP38

OPACAP6-38 200 $\mu \mathrm{M}$

๑Control PACAP6-38
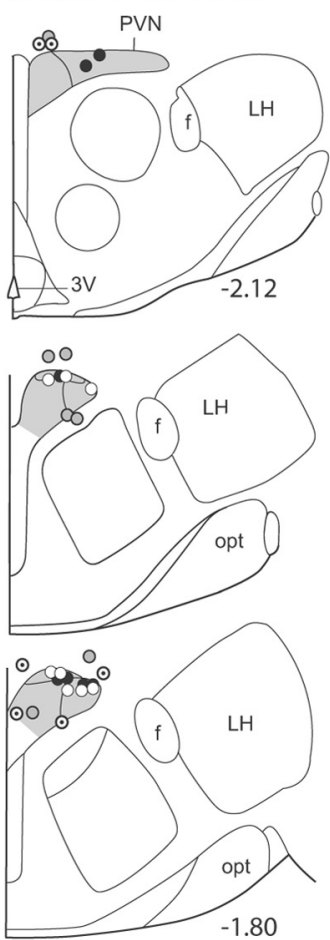

- Naratriptan $10 \mu \mathrm{M}$

oControl Naratriptan
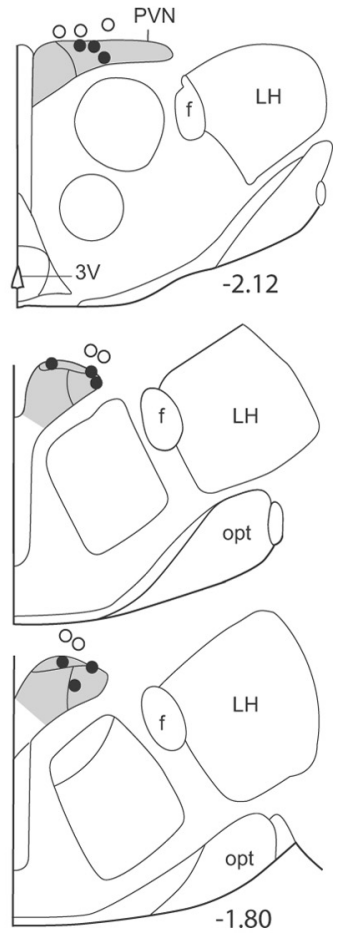

Figure 3. A, Experimental setup for simultaneous Sp5C electrophysiological recordings, hypothalamic microinjections, and meningeal receptive fields stimulations. $\boldsymbol{B}$, Summary of the histological findings of microinjections in the parvocellular aspect of the PVN and controls in neighboring areas. Numbers indicate distance from bregma. opt, Optic tract; LH, lateral hypothalamus; $f$, fornix.

Statistical analysis. One dura-sensitive neuron was studied per animal. Cumulative results are expressed as the mean \pm SEM of the percentage changes with regard to the mean values obtained before the cortical manipulation. Analyses were performed by comparing predrug and postdrug scores using Student's $t$ test and a two-tailed Wilcoxon signed rank test. Paired Student's $t$ test was also performed to determine significance between control and peak responses. The global impact of stress on muscimol effects was assessed from the areas under curves (AUCs) processed with two-way ANOVA followed by Bonferroni's post hoc multiple comparison tests. The levels of significance were set at $p<0.05$ and $p<0.01$.

\section{Results}

\section{Topographic organization of hypothalamo-trigeminal pathways}

Hypothalamic regions projecting to functionally characterized Sp5C trigeminovascular neurons were identified following iontophoretic injections of the retrograde tracer FG under electrophysiological control (Fig. 1A). All of these injection sites provided similar patterns of retrograde labeling within the PVN. We selected a small size injection site for presentation purposes. As shown in previous studies (Burstein et al., 1998; Noseda et al., 2010), neurons driven by meningeal and cutaneous periocular inputs are mainly located in the ventral Sp5C and upper cervical segments of the spinal cord $(\mathrm{C} 1 / \mathrm{C} 2)$. Injections of $\mathrm{FG}$ into $\mathrm{Sp} 5 \mathrm{C} / \mathrm{C} 1$ produced dense retrograde labeling of a cluster of cells located in the dorsomedial capsular, ventral, and posterior parts of the parvocellular aspect of the PVN, ipsilateral to the injection sites (Fig. 1C). These clusters of hypothalamo-trigeminal cells were observed in an area extending between -2.12 and -1.80 mm caudal to bregma, respectively (Paxinos and Watson, 1998). We also observed some retrograde labeled cells in other hypotha- lamic regions. Qualitative analyses of each rat showed that, compared to PVN, the amount of labeled neurons was very low, including scattered cells in the lateral hypothalamus and A11 region, and some few cells in the perifornical and retrochiasmatic nuclei.

Since FG can be taken and transported avidly by axons passing through, but not terminating in the injection sites (Dado et al., 1990), it is possible to obtain "false positive" retrograde labeling. To avoid this problem and to determine precisely the organization and distribution of PVN afferents in $\mathrm{Sp} 5 \mathrm{C} / \mathrm{C} 1$, the anterograde tracer BD was injected into the hypothalamic areas retrogradely labeled from Sp5C. Based on their restricted sizes and locations, representative cases were selected and further analyzed by comparing the pattern of labeling in the caudal medulla. Although a systematic study of anterograde tracer injections located in PVN regions neighboring to the area retrogradely labeled from $\mathrm{Sp} 5 \mathrm{C}$ was not performed, we did not observe descending projections to the Sp5C when some injection sites were located in these regions. Injections into PVN (Fig. 2B) resulted in dense labeling of fibers that terminated in the ipsilateral brainstem. Axonal terminal labeling consisting of thin fibers and small varicosities was restricted to Sp5C laminae I and outer II throughout its caudalmost aspect, including C1/C2 (Fig. 2C). Terminal labeling was also observed rostrally in the superior salivatory nucleus (SSN) (Fig. 2D). In agreement with previous anterograde tracing studies (Geerling et al., 2010), we also observed brainstem projections to other areas implicated in pain processing, including the ventrolateral periaqueductal gray matter (vPAG), the locus ceruleus and the parabrachial nucleus. 

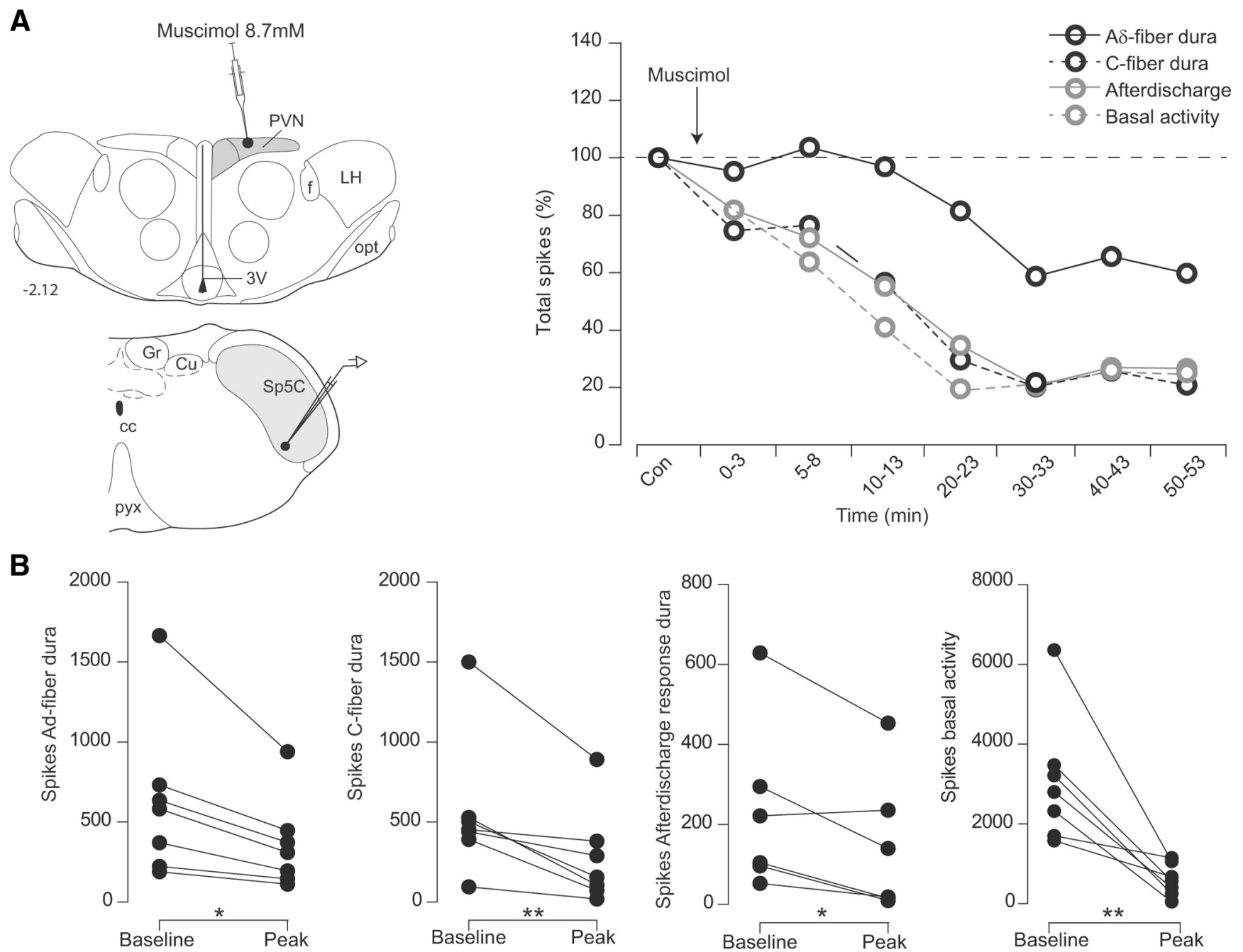

C
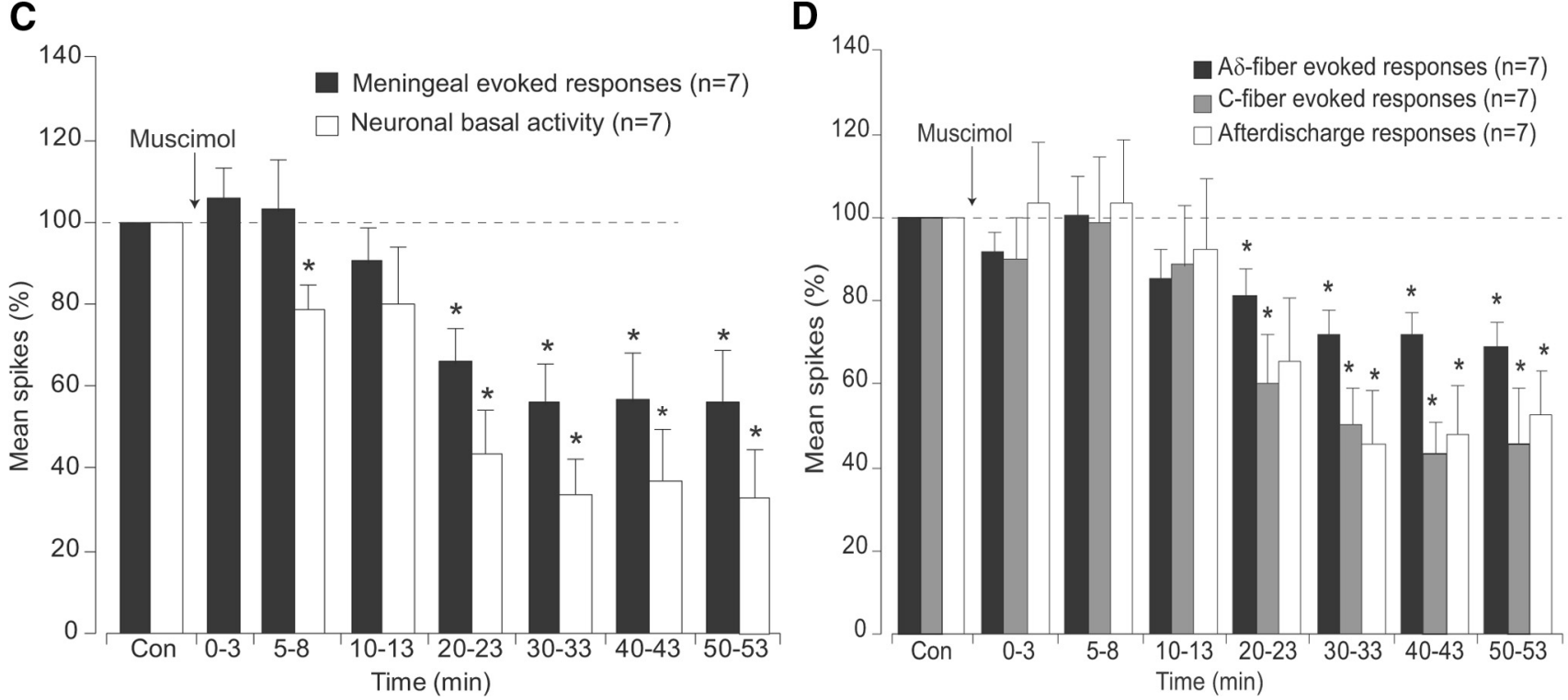

Figure 4. Effects of PVN microinjections of the GABA agonist muscimol, on the responses of trigeminovascular neurons simultaneously recorded in the Sp5C. $A$, Individual example of the effects on a Sp5 neuron of a muscimol microinjection $(200 \mathrm{nl}, 8.7 \mathrm{~mm})$ into parvocellular PVN cells. Background and meningeal $\mathrm{Sp} 5$ C nociceptive-evoked responses were depressed. $\boldsymbol{B}$, Peak reduction of $A \delta$ and C-fiber meningeal-evoked responses, afterdischarges, and background activities of each Sp5C neuron recorded following PVN microinjections of muscimol. C, D, Cumulative results showing the depressive effects of PVN infusions of muscimol on the nociceptive-evoked and background responses of Sp5C neurons. Results are expressed as mean \pm SEM of the percentage changes with regard to the mean values obtained before the PVN manipulation. ${ }^{*} p<0.05,{ }^{* *} p<0.01$. opt, 0 ptic tract; $3 \mathrm{~V}$, third ventricle; $\mathrm{f}$, fornix; LH, lateral hypothalamus; $\mathrm{cc}$, central canal; $\mathrm{Cu}$, cuneate nucleus; $\mathrm{Gr}$, gracile nucleus; pyx, pyramidal decussation. 
Table 1. Maximal effects obtained following intrahypothalamic (PVN) infusions of drugs on background and evoked Sp5C neuronal activities

\begin{tabular}{|c|c|c|c|c|c|c|c|}
\hline & \multicolumn{5}{|l|}{ Controls } & \multicolumn{2}{|l|}{ Stress } \\
\hline & $\begin{array}{l}\text { Meningeal-evoked } \\
\text { responses }\end{array}$ & $\begin{array}{l}\text { Basal } \\
\text { activity }\end{array}$ & $\begin{array}{l}\text { Spikes } A \delta \text {-fiber } \\
\text { dura }\end{array}$ & $\begin{array}{l}\text { Spikes C-fiber } \\
\text { dura }\end{array}$ & $\begin{array}{l}\text { Afterdischarge } \\
\text { responses }\end{array}$ & $\begin{array}{l}\text { Meningeal-evoked } \\
\text { responses }\end{array}$ & $\begin{array}{l}\text { Basal } \\
\text { activity }\end{array}$ \\
\hline Muscimol & $-56 \pm 8 \% *$ & $-44 \pm 10 \% *$ & $-81 \pm 7 \% *$ & $-60 \pm 12 \% *$ & $-45 \pm 13 \% *$ & $-71 \pm 17 \%^{*}$ & $-78 \pm 12 \% *$ \\
\hline Gabazine & $+153 \pm 17 \% *$ & $-79 \pm 5 \% *$ & $+119 \pm 6 \% *$ & $+121 \pm 9 \% *$ & $+154 \pm 16 \% *$ & & \\
\hline PACAP38 & $+112 \pm 14 \% *$ & $+142 \pm 17 \%^{*}$ & $-70 \pm 9 \%$ & $-80 \pm 14 \% *$ & $+137 \pm 15 \% *$ & & \\
\hline PACAP6-38 & $-60 \pm 6 \% *$ & $-78 \pm 10 \% *$ & $-76 \pm 4 \% *$ & $-70 \pm 11 \%^{*}$ & $-69 \pm 9 \% *$ & & \\
\hline Naratriptan & $-73 \pm 5 \% *$ & $-82 \pm 6 \%^{*}$ & $-77 \pm 6 \% *$ & $-81 \pm 5 \% *$ & $-89 \pm 7 \% *$ & & \\
\hline
\end{tabular}

Results are expressed as percentages of control responses before the microinjection. Negative values indicate depression, and positive values enhancement.

${ }^{*} p<0.05$ compared with control (Student's $t$ test and ANOVA).

\section{Selective hypothalamic modulation of Sp5C trigeminovascular activities}

Sp5C neurons presented a variable, mean tonic background activity of $30.5 \pm 5.4 \mathrm{~Hz}$ and were driven by both electrical stimulation of the dura and periocular brushing. Cumulative results revealed that supramaximal electrical stimulation of the dura (mean intensity, $0.8 \pm 0.07 \mathrm{~mA})$ produced both an early $(7 \pm 0.1$ $\mathrm{ms})$ and late $(45 \pm 0.6 \mathrm{~ms})$ peak of activation. Such latencies correspond to peripheral conduction velocities within the $A \delta$ fiber $(4.3 \mathrm{~m} / \mathrm{s})$ and C-fiber $(0.7 \mathrm{~m} / \mathrm{s})$ ranges, respectively (Noseda et al., 2010). Afterdischarges were also observed following repetitive electrical meningeal stimulation. Such increased responses were probably elicited by temporal summation mechanisms termed windup, a progressive increase in nociceptive trigeminal or spinal dorsal horn neuronal responses following repeated electrical stimulation of C-fibers, at a fixed intensity. Windup is thought to result from the temporal summation of NMDAreceptor-mediated slow cumulative depolarizations evoked by cutaneous nociceptive primary afferent input (D'Mello et al., 2011). Although windup does not amplify meningeal-evoked baseline responses (Bolton et al., 2005), it is possible that under our experimental conditions such temporal summation mechanisms elicited Sp5C prolonged excitability, since afterdischarges occurred even though the magnitude of peripheral input remained the same. As shown in the individual example (Fig. $4 A$ ), microinjections of the $\mathrm{GABA}_{\mathrm{A}}$ agonist muscimol within PVN strongly reduced both background, $\mathrm{A} \delta$ - and $\mathrm{C}$-fiber dura-evoked responses of the simultaneously recorded Sp5C neuron 5-10 min after the hypothalamic microinjection. Cumulative results showed that background and meningeal $\mathrm{A} \delta$ - and C-fiber evoked responses were significantly depressed by $43.7 \pm 10.4 \%, 81.1 \pm$ $6.8 \%$, and $60.2 \pm 11.7 \%$ of the control values, respectively, 20 min after muscimol, and lasted throughout the $60 \mathrm{~min}$ postinjection period (Fig $4 C, D$; Table 1 ).

Microinjections of the $\mathrm{GABA}_{\mathrm{A}}$ antagonist gabazine within PVN elicit an enhancement of meningeal evoked activities of Sp5C neurons 5-10 min after the hypothalamic microinjection (Fig. 5A). Cumulative results (Fig. 5C,D; Table 1) showed that facilitations were observed between 5-50 min after an injection. Meningeal $\mathrm{A} \delta$ - and C-fiber-evoked responses were significantly enhanced to $119.6 \pm 6.3 \%$ and $121.2 \pm 9.2 \%$ of the control values respectively, 20 and $30 \mathrm{~min}$, respectively, after gabazine. Background activities were reduced during the $30 \mathrm{~min}$ period that followed the injection, to $80.3 \pm 6.9 \%$ of the control values, $5 \mathrm{~min}$ after gabazine.

Hypothalamic PACAPergic modulation on Sp5C neurons after microinjections of the agonist PACAP38 into the PVN is shown in Figure 6 and Table 1. As illustrated in the individual example (Fig. 6A), microinjections of PACAP38 elicit significant enhancement of background activity of Sp5C neurons $15 \mathrm{~min}$ after the hypothalamic microinjection. Cumulative results showed that background activity was significantly enhanced to $142 \pm 17.0 \%$ of the control values $15 \mathrm{~min}$ after PACAP38 and lasted $60 \mathrm{~min}$ after microinjection (Fig. 6C,D). Only afterdischarges elicited by meningeal stimulation were enhanced between 5 and 60 min after microinjection. (136.9 $\pm 15.1 \%, 5 \mathrm{~min}$ after PACAP38) without modifying significantly $\mathrm{A} \delta$ - and C-fiber meningeal-evoked responses.

Microinjections of the PACAP antagonist PACAP6 - 38 within PVN depressed both background and meningeal-evoked nociceptive responses (Fig. 7). Cumulative results (Fig. 7C,D; Table 1) showed that depressions of background activities were obtained at $20 \mathrm{~min}$ after injection and lasted throughout the whole recording period ( $78.4 \pm 10.3 \%$ at $20 \mathrm{~min}$ after injection). Dura-evoked activities were reduced during almost the whole period that followed the injection $(76.4 \pm 4.3 \%$ and $70.5 \pm 11.6 \%$ for $\mathrm{A} \delta$ - and C-fiber evoked responses, respectively).

Microinjections of naratriptan within PVN inhibited both background and meningeal-evoked responses of Sp5C neurons (Fig. 8). As shown in the cumulative results (Fig. $8 C, D$; Table 1), the depressing effects of naratriptan on background activities were significant between 30 and $60 \mathrm{~min}$ (82.2 $\pm 5.8 \%$ at $30 \mathrm{~min}$ after naratriptan), whereas meningeal-evoked responses were depressed between 5 and 40 min after microinjection $(77.2 \pm 5.9 \%$ and $81.1 \pm 5.5 \%$ for $\mathrm{A} \delta$ at $5 \mathrm{~min}$ and $\mathrm{C}$-fiber at $20 \mathrm{~min}$, respectively).

\section{GABAergic-mediated hypothalamic inhibition of Sp5C trigeminovascular activities is reduced by acute stress} Rats placed on the elevated platform showed a dramatic increase in plasma corticosterone levels $(200.2 \pm 11.6 \mathrm{ng} / \mathrm{ml} ; n=8)$ compared to nonstressed rats $(84.3 \pm 12.3 \mathrm{ng} / \mathrm{ml} ; n=7 ; p<0.015)$. Electrophysiological recordings from Sp5C neurons were performed within a time frame between $2 \mathrm{~h} 30 \mathrm{~min}$ and $5 \mathrm{~h}$ after acute stress procedure (Fig. 9). As shown in Figure $9 B$ and Table 1 , AUC calculations indicate that the depressive effects of muscimol during the complete recording period were significantly reduced in stressed as compared to control animals ( $784 \pm 177 \%$ and $1996 \pm 326 \%$, respectively, for meningeal-evoked responses, $p<0.01 ; 1220 \pm 251 \%$ and $2149 \pm 248 \%$, respectively, for background activity, $p<0.05$ ).

\section{Discussion}

The present study provides precise information about the functional architecture of $\mathrm{PVN}$-descending trigeminal projections that are anatomically positioned to modulate both spontaneous and meningeal-evoked activities of trigeminovascular Sp5C neurons. Since PVN neurons are activated by noxious somatosensory stimuli (Condés-Lara et al., 2009), it is possible that these cells are part of feedback loops activated by noxious meningeal stimulation. We propose that direct descending influences from PVN 
A

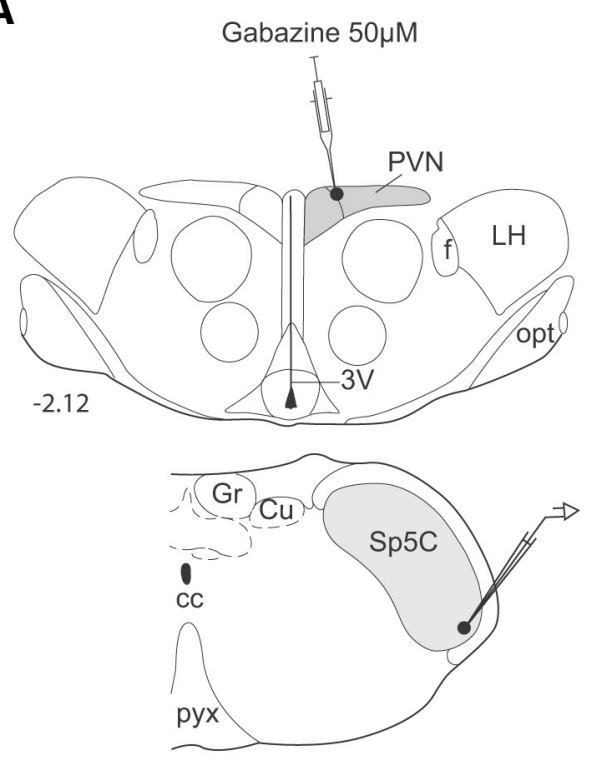

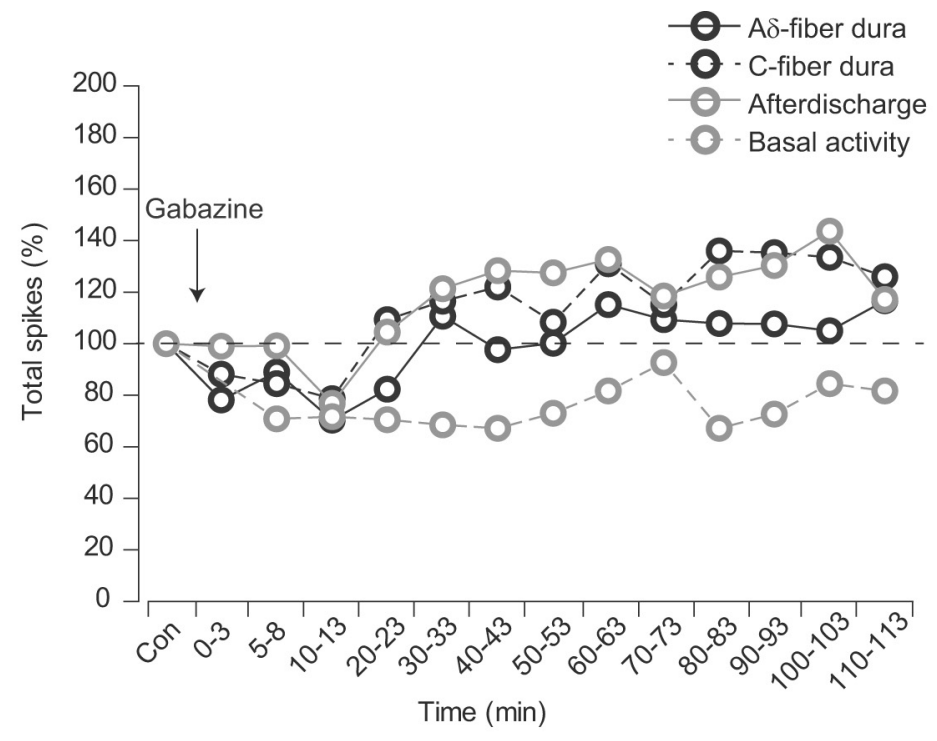

B
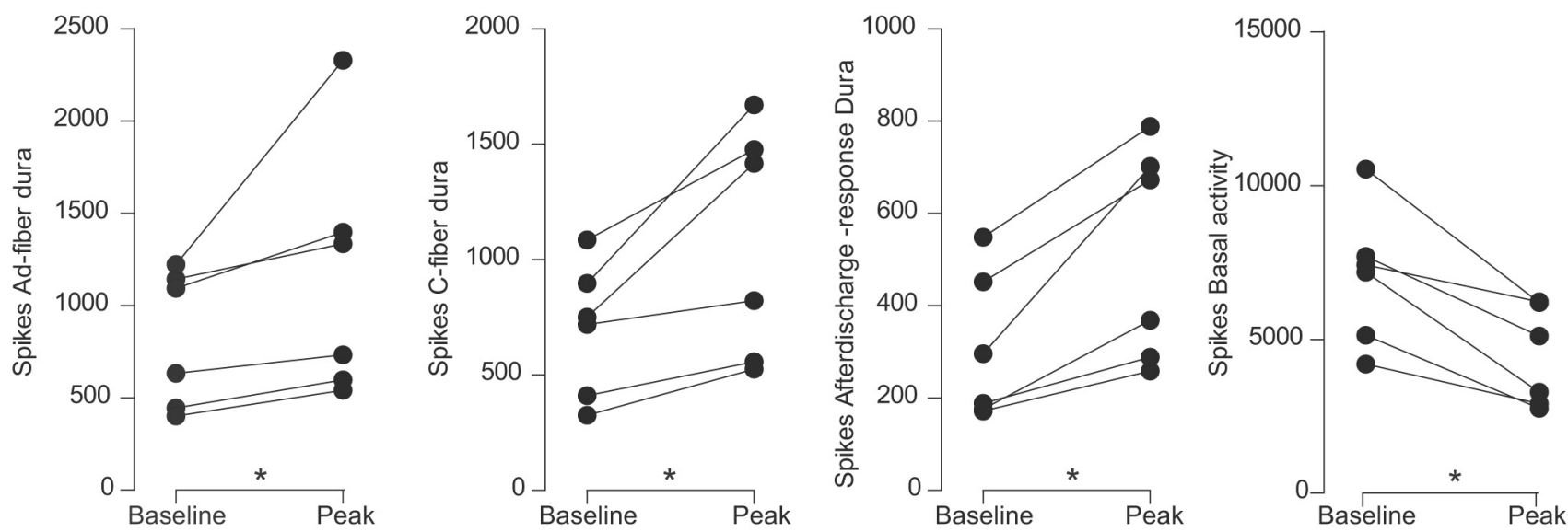

C

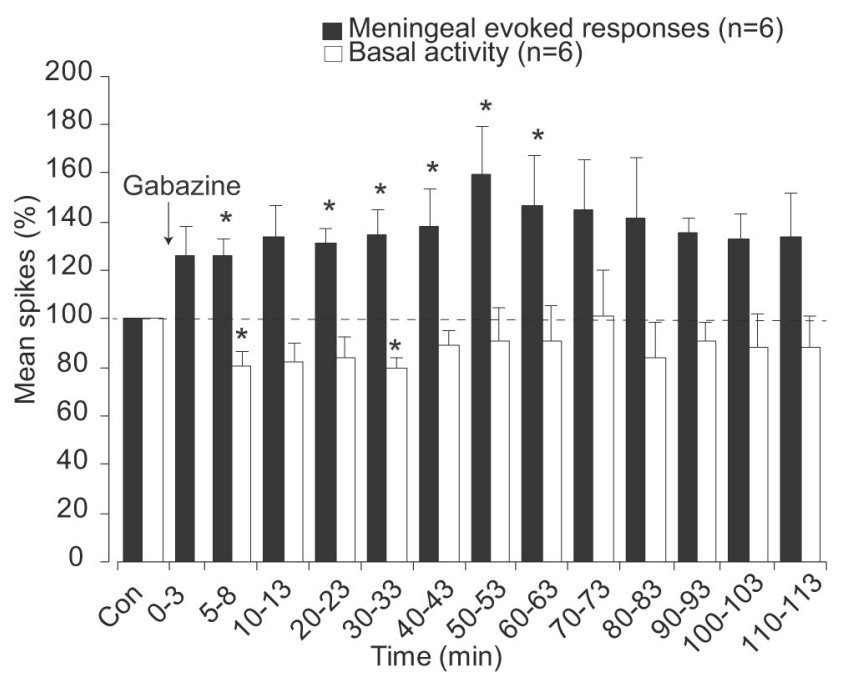

D

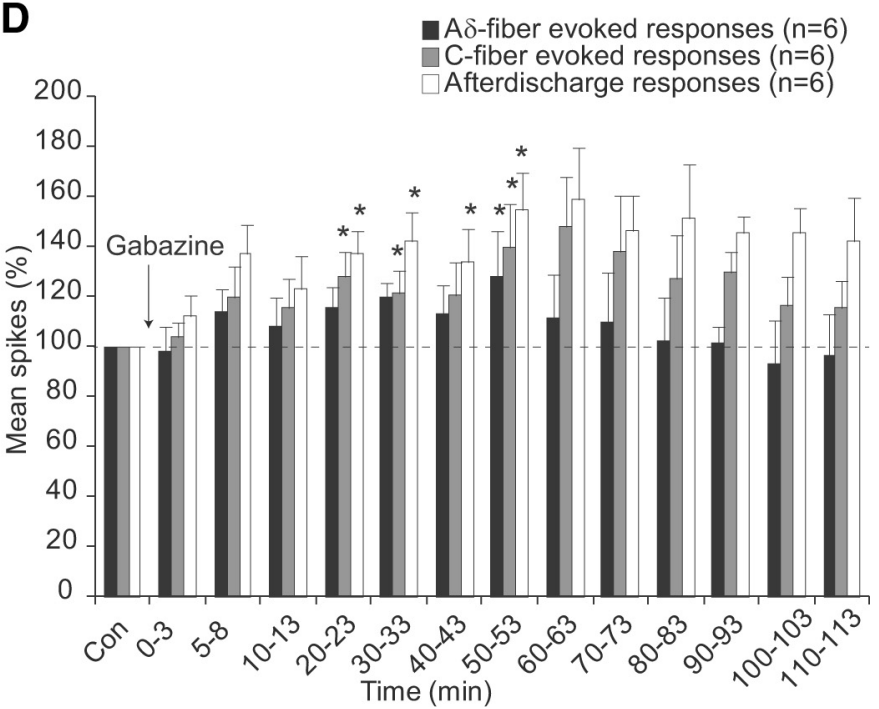

Figure 5. Effects of PVN microinjections of the $G_{A B A}$ antagonist gabazine on the responses of trigeminovascular neurons simultaneously recorded in the $S p 5 C$. $A$, Individual example of the effects on a Sp5 neuron of a gabazine microinjection $(200 \mathrm{nl}, 50 \mu \mathrm{m}$ ) into parvocellular PVN cells. Background responses were depressed, whereas meningeal nociceptive-evoked responses were facilitated in the Sp5C. $B$, Peak effects of A $\delta$ - and C-fiber meningeal-evoked responses, afterdischarges, and background activities of each Sp5C neuron recorded following gabazine infusion on PVN neurons. $C, D$, Cumulative results showing the effects of PVN manipulation with gabazine on the nociceptive-evoked and background responses of Sp5C neurons. Results are expressed as mean \pm SEM of the percentage changes with regard to the mean values obtained before the PVN manipulation. ${ }^{*} p<0.05$. Abbreviations are as in Figure 4. 

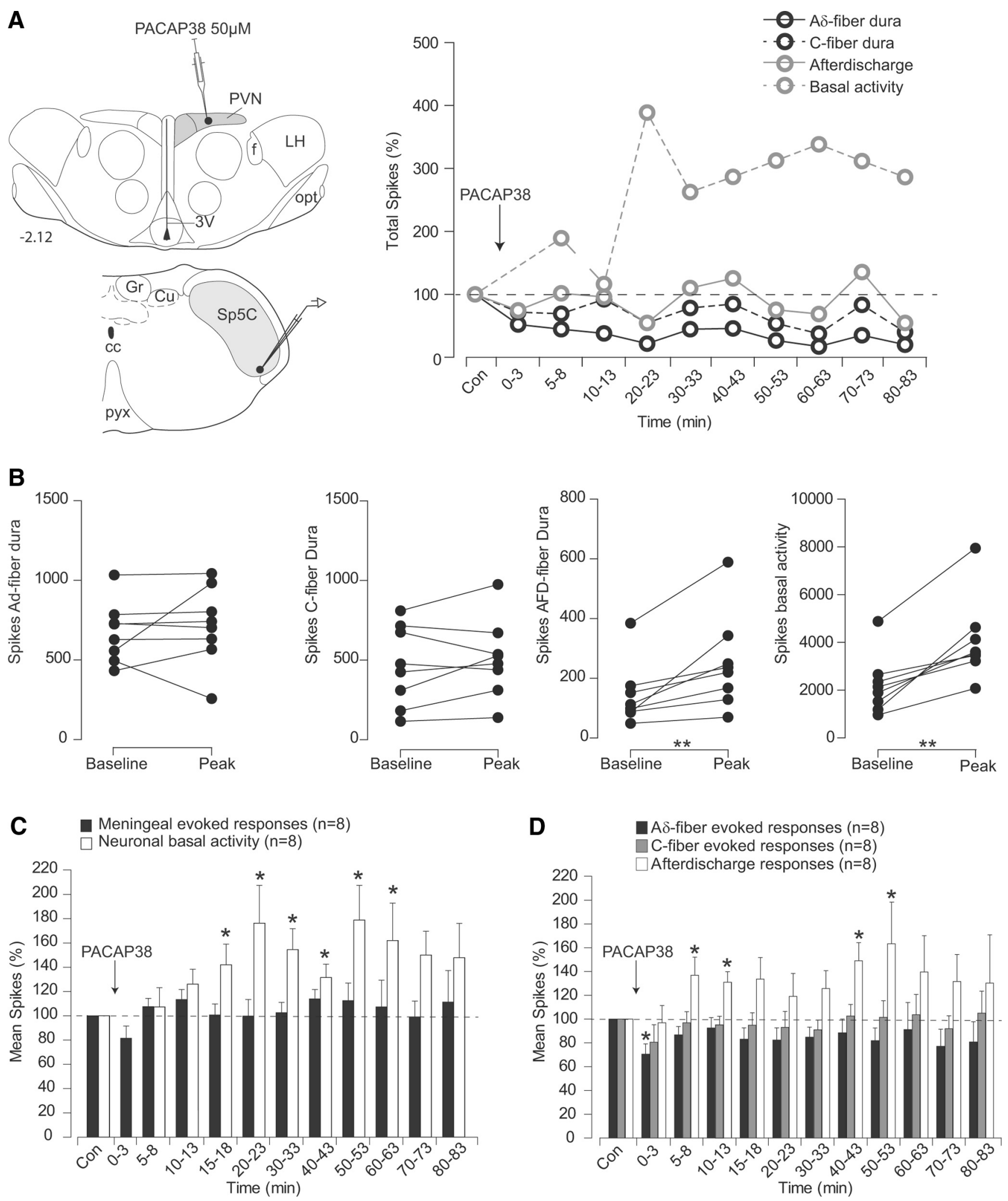

Figure 6. Effects of PVN microinjections of the PACAP agonist PACAP38 on the responses of trigeminovascular neurons simultaneously recorded in the $\mathrm{Sp} 5 \mathrm{C}$. $A$, Individual example of the effects on a Sp5 neuron of a PACAP38 microinjection ( $500 \mathrm{nl}, 10 \mu \mathrm{m}$ ) into parvocellular PVN cells. Background responses were enhanced in the Sp5C. $\boldsymbol{B}$, Peak effects of $A \delta$ - and C-fiber meningeal evoked responses, afterdischarges, and background activities of each Sp5C neuron recorded following PACAP38 infusion on PVN neurons. C, D, Cumulative results showing the effects of PVN manipulation with PACAP38 on the nociceptive-evoked and background responses of Sp5C neurons. Results are expressed as the mean \pm SEM of the percentage changes with regard to the mean values obtained before the PVN manipulation. ${ }^{*} p<0.05,{ }^{* *} p<0.01$. Abbreviations are as in Figure 4. 

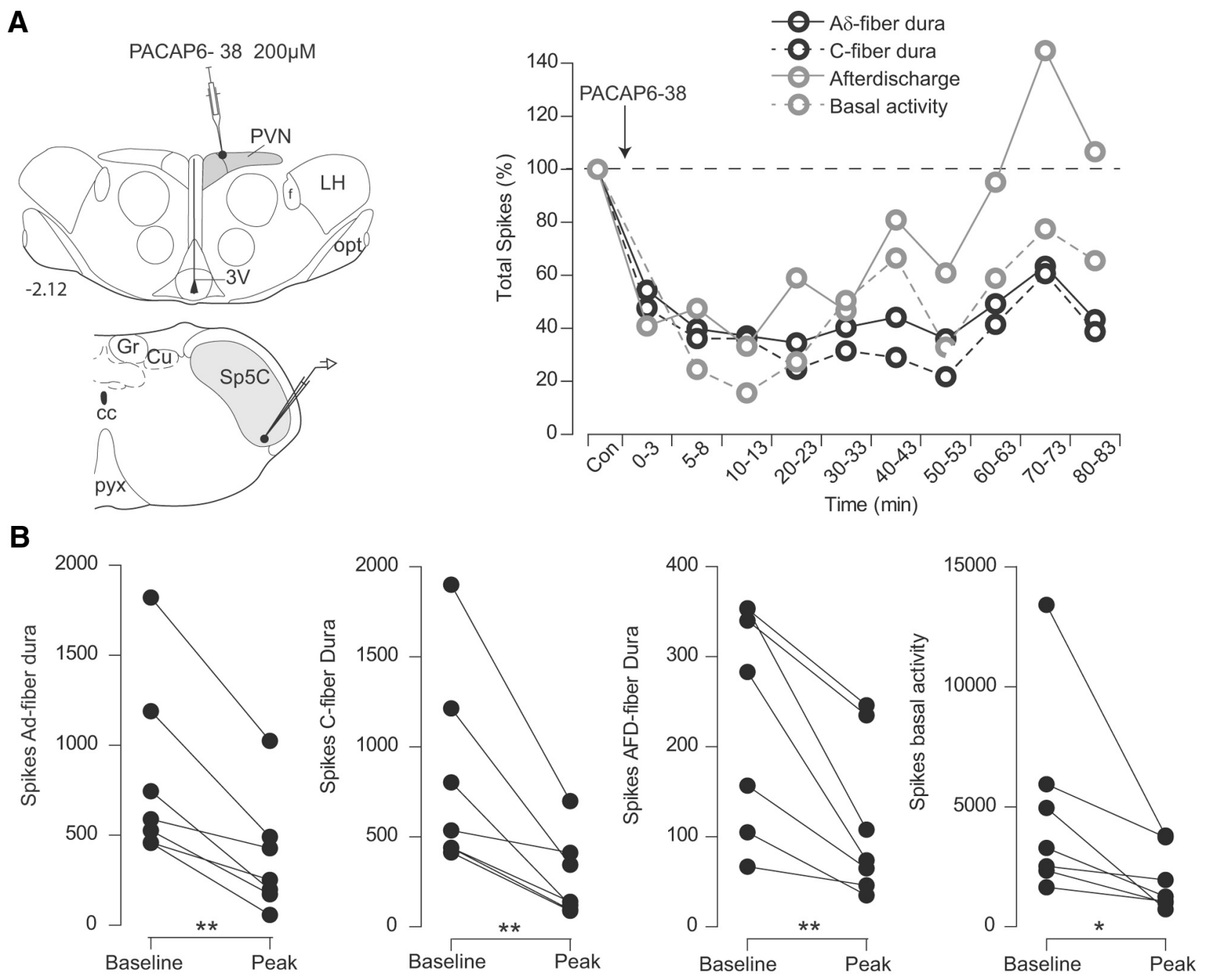

C

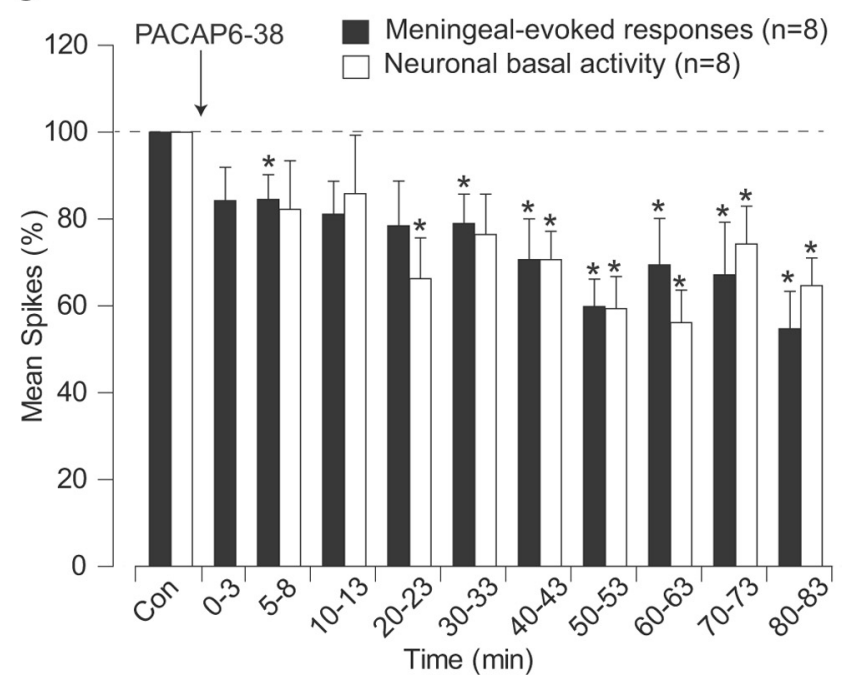

D

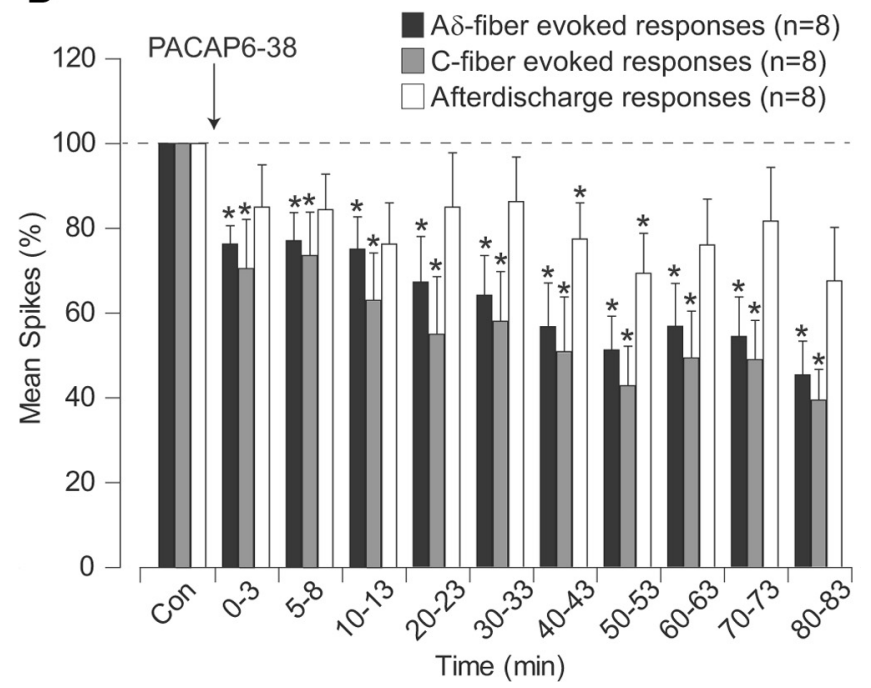

Figure 7. Effects of PVN microinjections of the PACAP antagonist PACAP6-38 on the responses of trigeminovascular neurons simultaneously recorded in the Sp5C. $A$, Individual example of the effects of a PACAP6-38 microinjection ( $500 \mathrm{nl}, 10 \mu \mathrm{m}$ ) into parvocellular PVN cells. Background and meningeal nociceptive-evoked responses were depressed in the Sp5C. $\boldsymbol{B}$, Peak reduction of A $\delta$ and C-fiber meningeal evoked responses, afterdischarges, and background activities of each Sp5C neuron recorded following PACAP6-38 infusion on PVN neurons. C, D, Cumulative results showing the depressive effects of PVN manipulation with PACAP6-38 on the nociceptive-evoked and background responses of Sp5C neurons. Results are expressed as the mean \pm SEM of the percentage changes with regard to the mean values obtained before the PVN manipulation. ${ }^{*} p<0.05,{ }^{* *} p<0.01$. Abbreviations are as in Figure 4. 

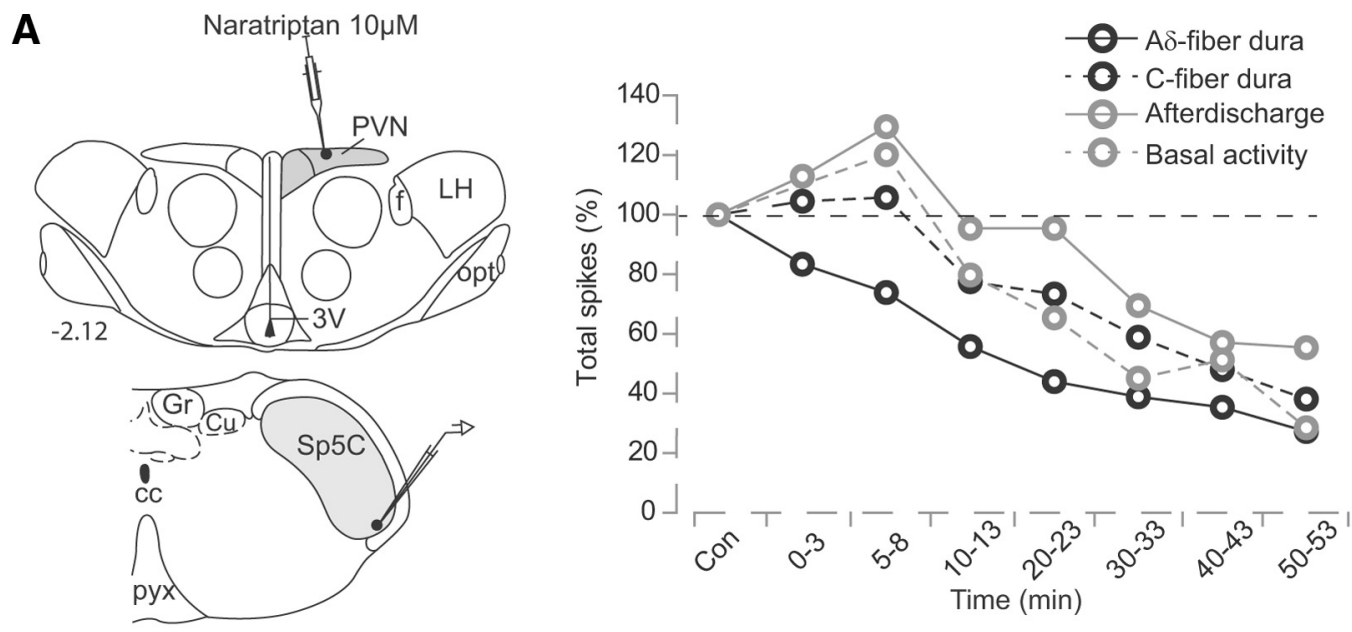

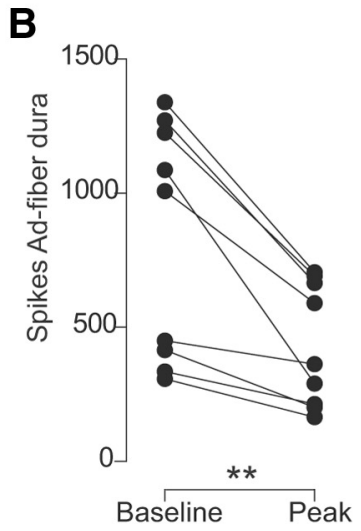

C

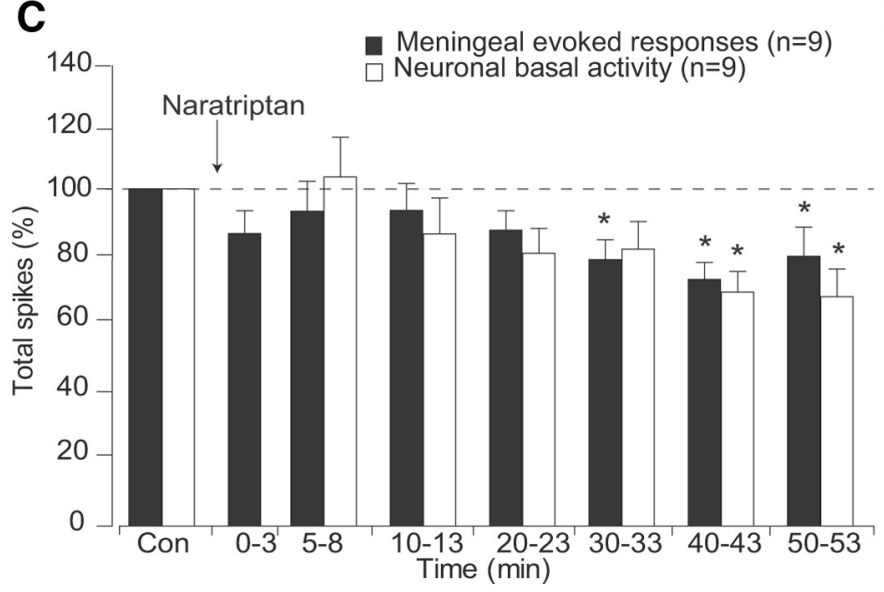

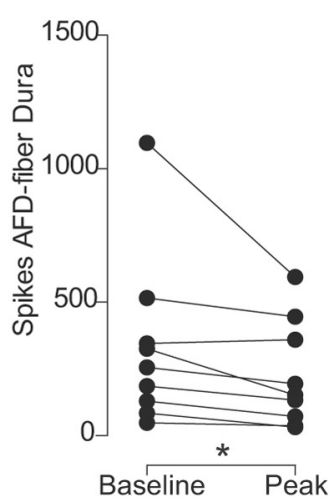

D

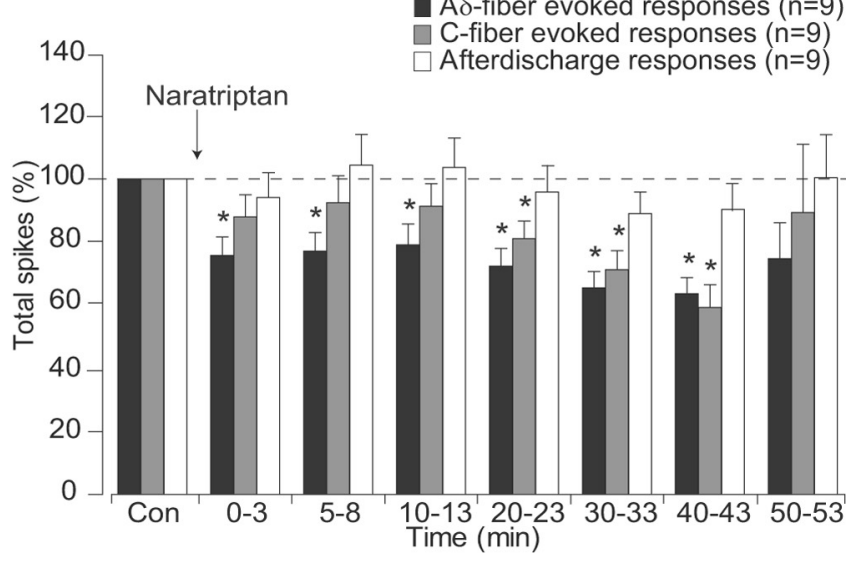

Figure 8. Effects of PVN microinjections of naratriptan on the responses of trigeminovascular neurons simultaneously recorded in the $\mathrm{Sp} 5 \mathrm{C}$. $A$, Individual example of the effects of a Naratriptan microinjection $(500 \mathrm{nl}, 10 \mu \mathrm{M})$ into parvocellular PVN cells. Background and meningeal nociceptive-evoked responses were depressed in the Sp5C. $\boldsymbol{B}$, Peak reduction of A $\delta$ - and C-fiber meningeal evoked responses, afterdischarges, and background activities of each Sp5C neuron recorded following naratriptan infusion on PVN neurons. $C, \boldsymbol{D}$, Cumulative results showing the depressive effects of PVN manipulation with naratriptan on the nociceptive-evoked and background responses of Sp5C neurons. Results are expressed as the mean \pm SEM of the percentage changes with regard to the mean values obtained before the PVN manipulation. ${ }^{*} p<0.05,{ }^{* *} p<0.01$. Abbreviations are as in Figure 4 .

neurons could act as modulators by inhibiting or facilitating meningeal-evoked activities following exogenous stimulation of nociceptors. Moreover, under certain circumstances, PVN cells could also act as endogenous central triggers, by enhancing background activities of $\mathrm{Sp} 5 \mathrm{C}$ cells in the absence of external stimulation. PVN neurons could regulate primary headaches processing by integrating nociceptive, autonomic, and stress processing mechanisms.
PVN-trigeminal projections to brainstem areas of trigeminovascular processing

Retrograde tracing labeled dense PVN projections to the Sp5C zone containing neurons driven by the ophthalmic branch of the trigeminal nerve. Descending axons originate ipsilaterally from clusters of PVN parvocellular cells and terminate in laminae I and outer II, which are dense targets of meningeal $\mathrm{A} \delta$ and $\mathrm{C}$ nociceptors. In accordance with other studies (Hosoya et al., 1990; 
Geerling et al., 2010), PVN parvocellular neurons project also to the $\mathrm{SSN}$, a region that gives rise to parasympathetic outflow to cephalic and ocular/nasal structures. PVN cells could modulate SSN neuronal activity that in turn influences postganglionic parasympathetic neurons in the sphenopalatine ganglion, resulting in vasodilation, plasma protein extravasation, and local release of inflammatory molecules (Delépine and Aubineau, 1997) that activate meningeal nociceptors. In this respect, a previous study showed that SSN stimulation activates both Sp5C neurons and elicited cranial autonomic reactions, which were inhibited by drugs currently effective in TACs treatments (Akerman et al., 2012). Interestingly, the same clusters of parvocellular PVN-trigeminal projecting cells are also densely labeled with corticotropin releasing hormone (Simmons and Swanson, 2009) and project to sympathetic and parasympathetic preganglionic neurons in the brainstem and spinal cord implicated in the autonomic aspect of the stress responses (Swanson and Sawchenko, 1980). Since PVN is implicated both in neurohormonal and autonomic integration of stress responses, it could likely act as a pivotal structure coordinating and integrating pain/anxiety comorbidity mechanisms involved in several primary headaches. Moreover, it is possible that in addition to direct, monosynaptic influences of PVN cells on CNS regions implicated trigeminovascular processing (Sp5C/SSN), part of PVN descending modulation occurs also indirectly, via brainstem regions involved in pain modulation such as the vPAG.

\section{PVN influences on brainstem trigeminovascular neurons: a direct link for top-down processing of headaches}

Restricted intrahypothalamic pharmacological manipulations allowed us to determine a variety of selective, top-down PVN modulatory influences on trigeminovascular Sp5C neurons. The differences in the latency and magnitude of the effects observed could be partly due to the variability of the injection locations, the small volumes used, and the diffusion ability of each drug. Nevertheless, unspecific effects can be ruled out since microinjections of the different drugs within PVN, when effective, always produced a selective unidirectional modulation of $\mathrm{Sp} 5 \mathrm{C}$ responses, as illustrated both in the individual examples and peak effects measured on each cell tested. We first investigated the role of $\mathrm{GABA}_{\mathrm{A}}$ receptor because PVN neurons re-
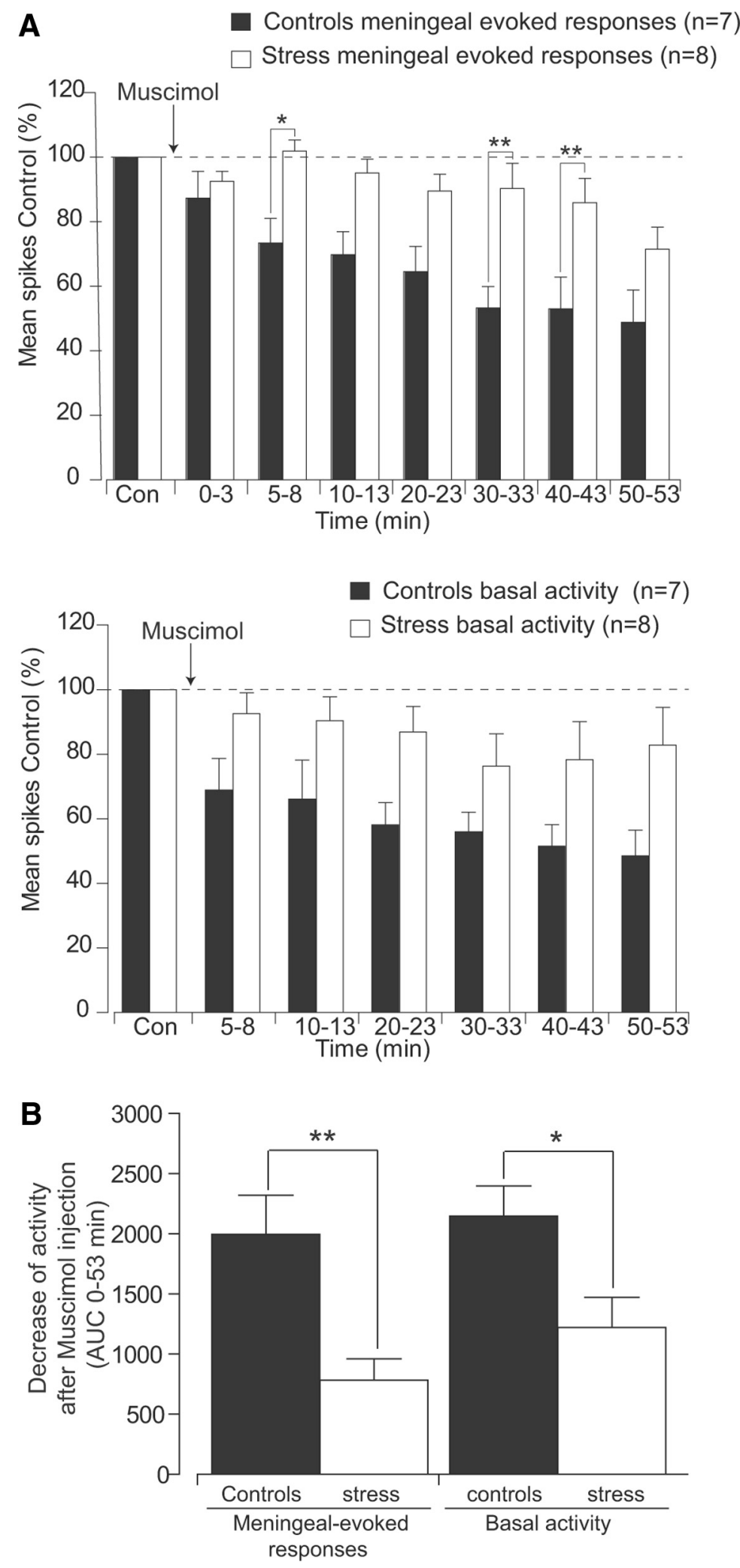

Figure 9. Acute stress reduces the depressive effects of PVN microinjections of the $\mathrm{GABA}_{\mathrm{A}}$ agonist muscimol $(200 \mathrm{nl}, 8.7 \mathrm{~mm})$ on the responses of trigeminovascular neurons simultaneously recorded in the $\mathrm{Sp} 5 \mathrm{C}$. $\boldsymbol{A}$, Cumulative results comparing the depressive effects of PVN manipulation with muscimol on meningeal nociceptive-evoked and background responses of Sp5C neurons, in controls (black) versus stressed (white) rats. Results are expressed as the mean \pm SEM of the percentage changes with regard to the mean values obtained before PVN manipulation. $B, A U C s$ of decreases in meningeal-evoked and basal activities during 53 min after muscimol injection. Each bar represents the mean \pm SEM of seven and eight independent determinations (control and stressed rats, respectively). Intergroup statistics comparing AUCs obtained between control and stressed rats were assessed with two-way ANOVA followed by Bonferroni's multiple comparison post hoc test. ${ }^{*} p<0.05,{ }^{* *} p<0.01$. 
ceive strong GABAergic inputs (Decavel and Van den Pol, 1990) and constitute a major fast inhibitory neurotransmitter in the PVN (Boudaba et al., 1996; Hermes et al., 1996). Our observations raise the possibility that PVN descending modulation is mainly excitatory, since local activation of $\mathrm{GABA}_{\mathrm{A}}$ receptor following muscimol microinjection into $\mathrm{PVN}$ induces significant depressive effects in all kinds of Sp5C neuronal properties, including baseline activity, evoked activations, and afterdischarges mediated by meningeal nociceptor stimulation. Conversely, $\mathrm{GABA}_{\mathrm{A}}$ receptor blockage following gabazine injections facilitated meningeal-evoked responses of Sp5C neurons while slightly reducing background activities, suggesting that PVN enhancement of Sp5C activities is only partially mediated by GABAergic disinhibition of excitatory PVN influences onto Sp5C neurons. Modulatory influences of $\mathrm{PVN}$ on spontaneous versus meningeal-evoked Sp5C activities could thus be mediated by different top-down mechanisms subserved by varied neuronal populations. This is also suggested by the facilitatory effects affecting exclusively background activities of Sp5C neurons following microinjections of the PACAP agonist PACAP38 in the PVN, without altering meningeal-evoked discharges. Such enhancement of Sp5C activities could be mediated by increases in firing rates of PVN neurons since administration of PACAP within the PVN increases neuronal firing rate and causes membrane depolarization (Uchimura et al., 1996). There is no clear explanation for the widespread depression of background and evoked responses following PACAP antagonist injections. PACAP6-38 was chosen on the basis of a relatively selective antagonism against PAC1-R receptors that are expressed in PVN neurons (Vaudry et al. 2009). It could be possible that in addition to PACAP antagonism, PACAP6 - 38 could have depressive actions on PVN cells that are not related only to its interaction with PACAP receptors. PACAP-immunoreactive fibers densely innervate corticotropinreleasing hormone $(\mathrm{CRH})$-containing neurons in the parvocellular PVN region (Légrádi et al., 1998), suggesting that PACAP inputs onto PVN neurons could elicit pronociceptive descending influences at the origin of headaches, while simultaneously regulating the hypothalamic-pituitary-adrenal axis (HPA) and thus stress responses. In this respect, upregulation of mRNAs encoding CRH in the PVN is PACAP dependent (Stroth et al., 2011), and behavioral studies using PACAP injections in the PVN (Norrholm et al., 2005) showed scored behaviors of stress that were increased in restrained animals, suggesting that PACAP could act as an excitatory neuropeptide that enhances responses to stress via CRH neurons. It is possible that centrally mediated PACAP effects could participate in the delayed migraine-like attacks observed only in migraineurs following systemic administration of PACAP38 (Schytz et al., 2009). However, some studies suggested that induction of migraine following PACAP38 infusion could be mediated peripherally, through the activation of meningeal nociceptors in the perivascular space of cranial arteries (Schytz et al., 2010) following degranulation of dural mast cells (Baun et al., 2012).

A parallel processing of both HPA and trigeminovascular activities at the PVN level is further supported by our data indicating that $\mathrm{GABA}_{\mathrm{A}}$-mediated inhibition of the excitatory output of PVN cells onto Sp5C neurons is significantly reduced by stress in the acutely restrained group. As shown previously (Hewitt et al., 2009), acute stress reduces the properties of $\mathrm{GABA}_{\mathrm{A}}$-inhibitory synapses impinging on parvocellular PVN neurons by downregulating the transmembrane anion transporter KCC2, which maintains low intracellular $\mathrm{Cl}^{-}$concentration, a prerequisite for the generation of $\mathrm{Cl}^{-}$hyperpolarizing $\mathrm{GABA}_{\mathrm{A}}$-mediated re- sponses. Although highly speculative, it is tempting to propose that such a loss of inhibition mediated by changes in the expression of KCC2 transporter could constitute one of the maladaptive mechanisms by which headaches may be generated primarily within the hypothalamus. However, our proposal is only based on indirect evidence, and thus numerous additional studies will be necessary to investigate this hypothesis.

Moreover, the depressive effects on both basal and meningealevoked Sp5C neuronal activity exerted by $5-\mathrm{HT} 1_{\mathrm{B} / \mathrm{D}}$ agonist naratriptan injections into the PVN could account for an entirely central mechanism. Central mechanisms at the origin of some TACs could play a fundamental role in the pathophysiology of such disorders, as shown by the persistence of cluster headache in a patient after total section of the trigeminal sensory root, which continued to respond to sumatriptan (Matharu and Goadsby, 2002).

As a whole, these findings support the possibility of a topdown modulation conveyed by PVN cells acting either on basal Sp5C activities or activated meningeal nociceptors. Such regulation could be mediated by sensory and autonomic PVN/ trigeminal-SSN outflow mechanisms, which could be altered by stress. An important question remains whether such hypothalamic controls could be simply interpreted as putative "attack generators," since they are also likely to influence, or be influenced by, sensory information conveyed by the trigeminovascular pathway.

\section{References}

Akerman S, Holland PR, Summ O, Lasalandra MP, Goadsby PJ (2012) A translational in vivo model of trigeminal autonomic cephalalgias: therapeutic characterization. Brain 135:3664-3675. CrossRef Medline

Alstadhaug KB (2009) Migraine and the hypothalamus. Cephalalgia 29: 809-817. CrossRef Medline

Baun M, Pedersen MH, Olesen J, Jansen-Olesen I (2012) Dural mast cell degranulation is a putative mechanism for headache induced by PACAP38. Cephalalgia 32:337-345. CrossRef Medline

Bolton S, O'Shaughnessy CT, Goadsby PJ (2005) Properties of neurons in the trigeminal nucleus caudalis responding to noxious dural and facial stimulation. Brain Res 1046:122-129. CrossRef Medline

Boudaba C, Szabó K, Tasker JG (1996) Physiological mapping of local inhibitory inputs to the hypothalamic paraventricular nucleus. J Neurosci 16:7151-7160. Medline

Bourgeais L, Noseda R, Chalus M, Hamon M, Villanueva L (2008) Functional architecture of hypothalamic networks that modulate brainstem trigeminovascular neurons in the rat: a link for trigeminal autonomic cephalalgias. Paper presented at 12th World Congress on Pain, Glasgow, UK, August.

Burstein R, Yamamura H, Malick A, Strassman AM (1998) Chemical stimulation of the intracranial dura induces enhanced responses to facial stimulation in brain stem trigeminal neurons. J Neurophysiol 79:964-982. Medline

Condés-Lara M, Rojas-Piloni G, Martínez-Lorenzana G, Rodríguez-Jiménez J (2009) Paraventricular hypothalamic oxytocinergic cells responding to noxious stimulation and projecting to the spinal dorsal horn represent a homeostatic analgesic mechanism. Eur J Neurosci 30:1056-1563. CrossRef Medline

Dado RJ, Burstein R, Cliffer KD, Giesler GJ Jr (1990) Evidence that FluoroGold can be transported avidly through fibers of passage. Brain Res 533: 329-333. CrossRef Medline

Decavel C, Van den Pol AN (1990) GABA: a dominant neurotransmitter in the hypothalamus. J Comp Neurol 302:1019-1037. CrossRef Medline

Delépine L, Aubineau P (1997) Plasma protein extravasation induced in the rat dura mater by stimulation of the parasympathetic sphenopalatine ganglion. Exp Neurol 147:389-400. CrossRef Medline

Denuelle M, Fabre N, Payoux P, Chollet F, Geraud G (2007) Hypothalamic activation in spontaneous migraine attacks. Headache 47:1418-1426. Medline

D’Mello R, Marchand F, Pezet S, McMahon SB, Dickenson AH (2011) Per- 
turbing PSD-95 interactions with NR2B-subtype receptors attenuates spinal nociceptive plasticity and neuropathic pain. Mol Ther 19:17801792. CrossRef Medline

Eckhorn R, Thomas U (1993) A new method for the insertion of multiple microprobes into neural and muscular tissue, including fiber electrodes, fine wires, needles and microsensors. J Neurosci Methods 49:175-179. CrossRef Medline

Geerling JC, Shin JW, Chimenti PC, Loewy AD (2010) Paraventricular hypothalamic nucleus: axonal projections to the brainstem. J Comp Neurol 518:1460-1499. CrossRef Medline

Hermes ML, Coderre EM, Buijs RM, Renaud LP (1996) GABA and glutamate mediate rapid neurotransmission from suprachiasmatic nucleus to hypothalamic paraventricular nucleus in rat. J Physiol 496:749-757. Medline

Hewitt SA, Wamsteeker JI, Kurz EU, Bains JS (2009) Altered chloride homeostasis removes synaptic inhibitory constraint of the stress axis. Nat Neurosci 12:438-443. CrossRef Medline

Hosoya Y, Sugiura Y, Ito R, Kohno K (1990) Descending projections from the hypothalamic paraventricular nucleus to the $\mathrm{A} 5$ area, including the superior salivatory nucleus, in the rat. Exp Brain Res 82:513-518. Medline

Légrádi G, Hannibal J, Lechan RM (1998) Pituitary adenylate cyclaseactivating polypeptide-nerve terminals densely innervate corticotropinreleasing hormone-neurons in the hypothalamic paraventricular nucleus of the rat. Neurosci Lett 246:145-148. CrossRef Medline

Leone M, Franzini A, Bussone G (2001) Stereotactic stimulation of posterior hypothalamic gray matter in a patient with intractable cluster headache. N Engl J Med 345:1428-1429. CrossRef Medline

Levy D, Strassman AM (2002) Mechanical response properties of A and C primary afferent neurons innervating the rat intracranial dura. J Neurophysiol 88:3021-3031. CrossRef Medline

Matharu MS, Goadsby PJ (2002) Persistence of attacks of cluster headache after trigeminal nerve root section. Brain 125:976-984. CrossRef Medline

Matharu MS, Cohen AS, McGonigle DJ, Ward N, Frackowiak RS, Goadsby PJ (2004) Posterior hypothalamic and brainstem activation in hemicrania continua. Headache 44:747-761. CrossRef Medline

Matharu MS, Cohen AS, Frackowiak RS, Goadsby PJ (2006) Posterior hypothalamic activation in paroxysmal hemicrania. Ann Neurol 59: 535-545. CrossRef Medline

May A (2009) New insights into headache: an update on functional and structural imaging findings. Nat Rev Neurol 5:199-209. CrossRef Medline

May A, Bahra A, Büchel C, Frackowiak RS, Goadsby PJ (1998) Hypothalamic activation in cluster headache attacks. Lancet 352:275-278. CrossRef Medline

May A, Bahra A, Büchel C, Turner R, Goadsby PJ (1999) Functional magnetic resonance imaging in spontaneous attacks of SUNCT: short-lasting neuralgiform headache with conjunctival injection and tearing. Ann Neurol 46:791-794. CrossRef Medline

Norrholm SD, Das M, Légrádi G (2005) Behavioral effects of local microinfusion of pituitary adenylate cyclase activating polypeptide (PACAP) into the paraventricular nucleus of the hypothalamus (PVN). Regul Pept 128: 33-41. CrossRef Medline

Noseda R, Monconduit L, Constandil L, Chalus M, Villanueva L (2008)
Central nervous system networks involved in the processing of meningeal and cutaneous inputs from the ophthalmic branch of the trigeminal nerve in the rat. Cephalalgia 28:813-824. CrossRef Medline

Noseda R, Constandil L, Bourgeais L, Chalus M, Villanueva L (2010) Changes of meningeal excitability mediated by corticotrigeminal networks: a link for the endogenous modulation of migraine pain. J Neurosci 30:14420-14429. CrossRef Medline

Paxinos G, Watson C (1998) The rat brain in stereotaxic coordinates. San Diego: Academic.

Robert C, Bourgeais L, Arreto CD, Condés-Lara M, Noseda R, Villanueva L (2012) Hypothalamic control of brainstem trigeminovascular nociception: a link for elucidating the pathophysiology of trigeminal autonomic cephalalgias. Paper presented at 14th World Congress on Pain, Milan, Italy, August.

Rocher C, Spedding M, Munoz C, Jay TM (2004) Acute stress-induced changes in hippocampal/prefrontal circuits in rats: effects of antidepressants. Cereb Cortex 14:224-229. CrossRef Medline

Schytz HW, Birk S, Wienecke T, Kruuse C, Olesen J, Ashina M (2009) PACAP38 induces migraine-like attacks in patients with migraine without aura. Brain 132:16-25. Medline

Schytz HW, Olesen J, Ashina M (2010) The PACAP receptor: a novel target for migraine treatment. J Am Soc Exp Neurother 7:191-196. CrossRef

Simmons DM, Swanson LW (2009) Comparison of the spatial distribution of seven types of neuroendocrine neurons in the rat paraventricular nucleus: toward a global 3D model. J Comp Neurol 516:423-441. CrossRef Medline

Stroth N, Liu Y, Aguilera G, Eiden LE (2011) Pituitary adenylate cyclaseactivating polypeptide controls stimulus-transcription coupling in the hypothalamic-pituitary-adrenal axis to mediate sustained hormone secretion during stress. J Neuroendocrinol 23:944-955. CrossRef Medline

Swanson LW, Sawchenko PE (1980) Paraventricular nucleus: a site for the integration of neuroendocrine and autonomic mechanisms. Neuroendocrinology 31:410-417. CrossRef Medline

Uchimura D, Katafuchi T, Hori T, Yanaihara N (1996) Facilitatory effects of pituitary adenylate cyclase-activating polypeptide (PACAP) on neurons in the magnocellular portion of the rat hypothalamic paraventricular nucleus (PVN) in vitro. J Neuroendocrinol 8:137-143. CrossRef Medline

Vaudry D, Falluel-Morel A, Bourgault S, Basille M, Burel D, Wurtz O, Fournier A, Chow BK, Hashimoto H, Galas L, Vaudry H (2009) Pituitary adenylate cyclase-activating polypeptide and its receptors: 20 years after the discovery. Pharmacol Rev 61:283-357. CrossRef Medline

Villanueva L, Le Bars D (1993) Computer-assisted reconstruction of axonal arborizations anterogradely labelled with the phaseolus vulgaris leucoagglutinin technique. J Neurosci Methods 50:217-224. CrossRef Medline

Xu L, Holscher C, Anwyl R, Rowan MJ (1998) Glucocorticoid receptor and protein/RNA synthesis-dependent mechanisms underlie the control of synaptic plasticity by stress. Proc Natl Acad Sci U S A 95:3204-3208. CrossRef Medline

Zimmermann M (1983) Ethical guidelines for investigations of experimental pain in conscious animals. Pain 16:109-110. CrossRef Medline

Zurak N (1997) Role of the suprachiasmatic nucleus in the pathogenesis of migraine attacks. Cephalalgia 17:723-728, 1997. CrossRef Medline 